\title{
An Experimental and Modeling Study on the Response to Varying Pore Pressure and Reservoir Fluids in the Morrow A Sandstone
}

\author{
Aaron V. Wandler, Thomas L. Davis, and Paritosh K. Singh \\ Department of Geophysics, Colorado School of Mines, 1500 Illinois Street, Golden, CO 80401, USA \\ Correspondence should be addressed to Aaron V. Wandler, awandler@mymail.mines.edu
}

Received 9 August 2011; Accepted 29 September 2011

Academic Editor: Marek Grad

Copyright (C) 2012 Aaron V. Wandler et al. This is an open access article distributed under the Creative Commons Attribution License, which permits unrestricted use, distribution, and reproduction in any medium, provided the original work is properly cited.

\begin{abstract}
In mature oil fields undergoing enhanced oil recovery methods, such as $\mathrm{CO}_{2}$ injection, monitoring the reservoir changes becomes important. To understand how reservoir changes influence compressional wave $(\mathrm{P})$ and shear wave $(\mathrm{S})$ velocities, we conducted laboratory core experiments on five core samples taken from the Morrow A sandstone at Postle Field, Oklahoma. The laboratory experiments measured $\mathrm{P}$ - and S-wave velocities as a function of confining pressure, pore pressure, and fluid type (which included $\mathrm{CO}_{2}$ in the gas and supercritical phase). P-wave velocity shows a response that is sensitive to both pore pressure and fluid saturation. However, S-wave velocity is primarily sensitive to changes in pore pressure. We use the fluid and pore pressure response measured from the core samples to modify velocity well logs through a log facies model correlation. The modified well logs simulate the brine- and $\mathrm{CO}_{2}$-saturated cases at minimum and maximum reservoir pressure and are inputs for full waveform seismic modeling. Modeling shows how P- and S-waves have a different time-lapse amplitude response with offset. The results from the laboratory experiments and modeling show the advantages of combining P- and S-wave attributes in recognizing the mechanism responsible for time-lapse changes due to $\mathrm{CO}_{2}$ injection.
\end{abstract}

\section{Introduction}

Currently, there are 128 enhanced oil recovery (EOR) projects worldwide using $\mathrm{CO}_{2}$ injection as a tertiary recovery method, with 113 taking place in the United States [1]. Often the criterion for successful seismic monitoring of $\mathrm{CO}_{2}$ projects is the ability to collect high-resolution seismic data, since seismic methods have shown to be very effective in detecting time-lapse changes [2-6]. The effectiveness of seismic monitoring depends upon the changes in acoustic and elastic impedance caused by injection and production. These changes are then observed in the amplitude and travel time of seismic waves.

Time-lapse seismic methods utilizing compressional waves (P-wave) and shear waves ( $\mathrm{S}$-wave) can ideally improve the identification of flooded or pressurized compartments within the reservoir during a $\mathrm{CO}_{2}$ EOR operation. The use of $\mathrm{P}$-wave data is not a definitive method for pressure detection, but the addition of S-wave data may provide a distinction between a gas-bearing zone and a zone of high pore pressure
[7], this is a motivation for using S-waves as a time-lapse tool. An example provided by Xue et al. [8] explains if an observed time-lapse P-wave anomaly is caused by a decrease in velocity without an associated S-wave anomaly, the zone has most likely been flushed with $\mathrm{CO}_{2}$ without any changes in pore pressure. However, if the S-wave data show a similar anomaly, due to a reduction in velocity, the zone may have undergone a pore pressure buildup in addition to being flushed with $\mathrm{CO}_{2}$. Identifying the impact of changing stresses within the reservoir is as important as recognizing the effects of saturation.

Saturation effects are typically estimated from fluid substitution modeling (e.g., Gassmann [9] and Kuster and Toksoz [10]). Since fluid substitution methods do not directly account for changing rock properties with respect to varying pore pressure, additional information must be used to account for the effects of pore pressure. This additional information may be obtained from, for example, reservoir flow simulation or experimental core studies. The purpose of this paper is to show how the results from rock physics 
experiments that include saturation and pore pressure variation can be used to estimate amplitude changes in a reservoir undergoing $\mathrm{CO}_{2}$ injection.

The contribution of this study applies directly to a major ongoing research project at Colorado School of Mines. The Reservoir Characterization Project (RCP) is a consortium at Colorado School of Mines whose research goal is to monitor $\mathrm{CO}_{2}$ EOR projects to effectively manage and enhance the recovery process. The RCP has used $\mathrm{P}-$, S-, and convertedwave (PS) time-lapse seismic acquisition to monitor $\mathrm{CO}_{2}$ floods for EOR. The RCP conducted the first ever timelapse, multicomponent seismic survey in conjunction with a $\mathrm{CO}_{2}$ huff-n-puff project at Vacuum Field, New Mexico. Multicomponent time-lapse seismic data was used to monitor the EOR project at Weyburn Field, Saskatchewan, Canada. The current research project is a time-lapse study of an incised valley fill system undergoing a water alternating gas (i.e., $\mathrm{CO}_{2}$ ) injection scheme for EOR at Postle Field, Texas County, Oklahoma, located in the Anadarko Basin. The results from the experiment and analysis reflect the use of reservoir core samples and actual reservoir fluids. The aim of this work is to provide insight related directly to this specific type of environment.

1.1. Previous Work. Studies on the effects of saturation, pressure, and pore fluid have been documented as early as 1966 [12]. King [12] reported on the change in velocities of five sandstone samples saturated with air, an $\mathrm{NaCl}$ solution, and kerosene as a function of hydrostatic confining pressure and internal pore pressure. Furthermore, Domenico [13] showed that $\mathrm{S}$-wave velocity is more sensitive to increasing differential pressure than $\mathrm{P}$-wave velocity in three sandstone cores of low, intermediate, and high porosity.

A series of papers have been published on the results of the P-wave velocity response to the migration of $\mathrm{CO}_{2}$ in water-saturated sandstones using an experimental setup that simulates cross-well seismic profiling. Xue et al. [8] mapped the velocity changes caused by $\mathrm{CO}_{2}$ injection in water-saturated Tako and Shirahama sandstones at constant pore pressure. In a similar experiment, Xue and Ohsumi [14] mapped the velocity changes caused by the injection of gas, liquid, and supercritical phase $\mathrm{CO}_{2}$ into a watersaturated Tako sandstone. They investigated the changes in velocity with increasing pore pressure and concluded that $\mathrm{CO}_{2}$ injection causes larger velocity changes than the change associated with increasing pore pressure in their core samples. In addition to the P-wave velocity, strain was measured as a function of hydrostatic pressure in a dry sample. Their observations showed how strain normal and parallel to the bedding plane are not equal and more deformation occurred normal to the bedding plane. To improve upon their crosswell seismic profiling experiment and the accuracy of the $\mathrm{P}$-wave velocity changes relative to the $\mathrm{CO}_{2}$ injection, Xue and Lei [15] applied a difference tomography method to the measured slowness. This technique correlated areas of higher porosity with greater velocity reduction. Velocity reduction when $\mathrm{CO}_{2}$ was in liquid or supercritical phase was twice as much as when in the gas phase. From the same dataset as Xue and Lei [15], Shi et al. [16] focused on P-wave velocity reductions due to supercritical $\mathrm{CO}_{2}$ displacement of pore water, where the velocity reductions deviated significantly from the Gassmann-predicted velocities for both patchy and uniform saturations. Lei and Xue [17] expanded on the results of Xue and Lei [15] and Shi et al. [16] and showed that P-wave velocity decreased, and the attenuation coefficient increased, due to gaseous, liquid, and supercritical $\mathrm{CO}_{2}$ partially replacing pore water. Kim et al. [18] also investigated the use of P-wave velocity and resistivity as a way to monitor saturation of a sandstone during a $\mathrm{CO}_{2}$ injection process. This was accomplished by injecting supercritical $\mathrm{CO}_{2}$ into a water-saturated Berea sandstone sample at simulated reservoir conditions.

The effects of saturation, pore pressure, and effective stress, studied on sandstone core samples from the Northwest Shelf of Australia, show that the $\mathrm{V}_{P} / \mathrm{V}_{S}$ ratio is an indicator for the saturation state between oil-saturated and the dry state [19]. Siggins [20] also studied the response of $\mathrm{CO}_{2}$ saturated sandstones at in-situ reservoir conditions for two synthetic sandstones and one reservoir sandstone/mudstone from the Otway Basin, C seam, Waarre Formation. His findings were both $\mathrm{P}$-wave and $\mathrm{S}$-wave velocities decreased when the samples were saturated with liquid $\mathrm{CO}_{2}$, compared to dry rock. Also, the synthetic sandstones showed better agreement with Gassman's fluid substitution theory than did the reservoir sandstone. Similarly, Siggins et al. [21] compared synthetic sandstones and Waarre C formation reservoir sandstones when dry and saturated with gaseous and liquid-phase $\mathrm{CO}_{2}$. Larger changes were observed in both $\mathrm{P}$-wave and $\mathrm{S}$-wave velocity when $\mathrm{CO}_{2}$ was in the liquid phase.

The effects of saturation and pore pressure have also been studied with respect to the effective pressure law and the effective pressure coefficient $[22,23]$ and how fractures change the constituency of the rock and the effective pressure coefficient [24]. The work by $\mathrm{Xu}$ et al. [24] on effective pressure shows the importance of why assuming the effective pressure coefficient to be unity could lead to significant errors when predicting time-lapse changes.

The RCP has used experimental rock physics to understand how the changes in confining pressure, pore pressure, and fluid saturation affect $\mathrm{P}$-wave and S-wave velocities. This knowledge has then been applied to the interpretation of multicomponent time-lapse surface seismic monitoring. Capello [25] used rock physics as a feasibility study for seismic monitoring of a $\mathrm{CO}_{2}$ huff-n-puff flood in the Permian San Andres Formation, a dolomitized carbonate deposit at Vacuum Field. Also using samples from the San Andres Formation, Duranti [26] investigated the coexistence of equant pores and fractures and found that a dual porosity rock physics model was more successful in predicting the changes in differential pressure and saturation observed in the experimental data.

Brown [27] integrated experimental rock physics measurements from the carbonate Marly beds of the Mississippian Charles Formation to improve the interpretation of time-lapse seismic data for the monitoring of a $\mathrm{CO}_{2}$ flood at Weyburn Field. Yamamoto [28] included the rock physics results obtained by Brown [27] to improve the flow modeling 
TABLE 1: Depth, density, porosity, and permeability of core samples from three different lithological zones.

\begin{tabular}{lccccc}
\hline Sample & $\begin{array}{c}\text { Depth } \\
(\mathrm{m})\end{array}$ & $\begin{array}{c}\text { Density } \\
\left(\mathrm{gm} / \mathrm{cm}^{3}\right)\end{array}$ & $\begin{array}{c}\text { Porosity } \\
(\%)\end{array}$ & $\begin{array}{c}\text { Permeability }(\mathrm{mD}) \\
\text { Preexperiment }\end{array}$ & $\begin{array}{c}\text { Permeability }(\mathrm{mD}) \\
\text { Postexperiment }\end{array}$ \\
\hline Cemented & 1875 & 2.394 & 11.54 & 10.6 & 6.67 \\
High permeability no. 1 & 1878 & 2.105 & 19.96 & 270 & 192 \\
High permeability no. 2 & 1879 & 2.067 & 22.64 & 123 & 105 \\
Lower permeability no. 1 & 1888 & 2.179 & 18.73 & 11.0 & 11.0 \\
Lower permeability no. 2 & 1888 & 2.104 & 20.84 & 68.8 & 26.8 \\
\hline
\end{tabular}

of $\mathrm{CO}_{2}$ by minimizing the difference between calculated and observed acoustic impedance while simultaneously matching the production history.

Lastly, Rojas [29] measured dry rock velocities for the purpose of analyzing the different responses from Gassmann fluid substitution. This study on tight gas sands linked $\mathrm{V}_{P} / \mathrm{V}_{S}$ sensitivity to pore pressure changes, lithology, and fluid content to aid in identifying zones with a higher reservoir potential of the Late Cretaceous Williams Fork Formation at Rulison Field, CO.

Perhaps the earliest and most cited laboratory experiment related to monitoring a $\mathrm{CO}_{2}$ EOR operation is that by Wang and Nur [30]. They measured ultrasonic P-wave and Swave velocities on seven sandstones and one unconsolidated sand saturated with n-hexadecane and then flushed with $\mathrm{CO}_{2}$. Their measurements were done at constant confining pressure over a range of pore pressures and temperatures above and below the critical point of $\mathrm{CO}_{2}$. Their findings show a significant decrease in $\mathrm{P}$-wave velocity which was attributed to $\mathrm{CO}_{2}$ saturation. The $\mathrm{S}$-wave velocity exhibited a greater effect to pore pressure than saturation and was shown to be less sensitive to saturation.

Outside of research done on the Tako, Shirahama, Waarre C Formation, Williams Fork Formation sandstones and the carbonates of San Andres and Charles Formation, most of the experimental studies are not done on reservoir samples obtained from well core. This is evident in the statement made by Siggins et al. [21], "literature on laboratory measurements of the effects of $\mathrm{CO}_{2}$ on the seismic properties of reservoir rocks is relatively sparse."

\section{Postle Field Overview}

The geologic environment of the producing reservoir at Postle Field is the Upper Morrow sandstone Formation, which is a Pennsylvanian-age siliciclastic incised valley fill system. Typical Morrow sediments consist of shales punctuated by valley fill sand deposits [31]. The Morrow Formation is encased between two high-stand limestones [32]. The upper boundary is a conformable surface at the base of the Atoka Thirteen Fingers Limestone. The lower boundary of the Morrow Formation is an unconformable surface above the Mississippian Chester Limestone. The deposition of Postle Field during Pennsylvanian time was a relative sea-level low-stand shoreline where the Morrow Formation is much sandier [33]. The primary producing unit in the Morrow Formation is the Upper Morrow A, A1, and A2 sands. In
Postle Field, the producing formation that is undergoing the $\mathrm{CO}_{2}$ flood is the Morrow A sandstone.

Postle Field is a large mature oil field undergoing a water alternating gas (WAG) flood for enhanced oil recovery of the Morrow A sandstone. The volume of water to $\mathrm{CO}_{2}$ injected into the reservoir is referred to as the WAG ratio and is expressed in reservoir volumes at reservoir conditions. The average WAG ratio implemented at Postle Field is 0.35 to 1 . The reservoir pressure is maintained above the minimum miscibility pressure of $14.48 \mathrm{MPa}$ by injecting water and $\mathrm{CO}_{2}$ at $29.65 \mathrm{MPa}$ and by keeping the bottom hole pressure of a producing well higher than $6.89 \mathrm{MPa}$ [34].

\section{Sample Selection}

We retrieved five core plug samples from three different lithological zones within the Morrow A sandstone interval. The three zones were a low-porosity and low-permeability cemented zone, a higher-porosity and high-permeability zone, and a higher-porosity and lower-permeability zone. Each sample was cut parallel to the bedding plane. The cylindrical dimensions of the samples were roughly $3.81 \mathrm{~cm}$ in length and $2.54 \mathrm{~cm}$ in diameter. The depths from where the core samples were retrieved, as well as density, porosity, and permeability are listed in Table 1.

3.1. Mineralogy. We used QEMSCAN (quantitative evaluation of minerals by scanning electron microscopy) to quantitatively evaluate mineral content on each of the three lithological zones. The cemented zone (Figure 1) consists of subrounded quartz grains cemented by ankerite and kaolinite clay. This cemented zone shows a lower amount of grain-to-grain contact which suggests the possibility of early cementation. The lower amount of grain-to-grain contact is likely related to the presence of ankerite which may indicate that the pore water was rich in iron. In addition, there are occurrences of angular overgrowths over subrounded quartz grains. Even though the QEMSCAN measured 14\% porosity, most of the porosity for this cemented zone is interstitial between the fine-grained kaolinite clay.

The higher-porosity and high-permeability zone (Figure 2) consists mostly of subrounded quartz grains with lesser amounts of kaolinite clay cement, where most of the porosity (25\%) occurs between quartz grains. Unlike the other zones, only a trace amount of Ankerite occurs as cement.

The higher-porosity and lower-permeability zone (Figure 3 ) consists mostly of subrounded quartz grains with lesser 

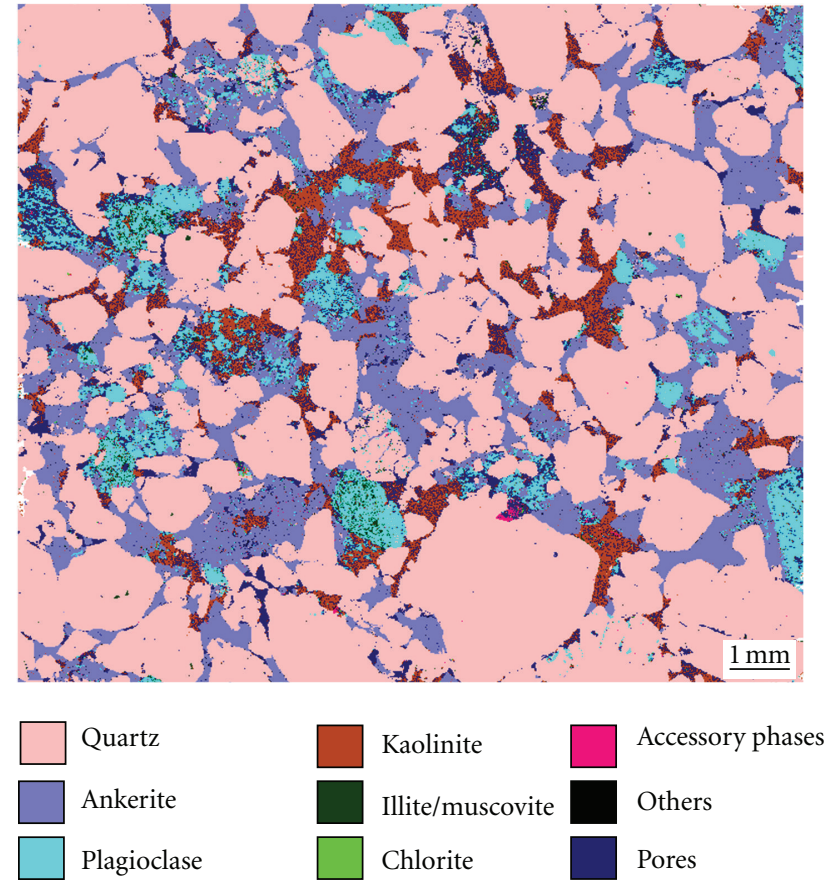

FIGURE 1: QEMSCAN image from the cemented zone.
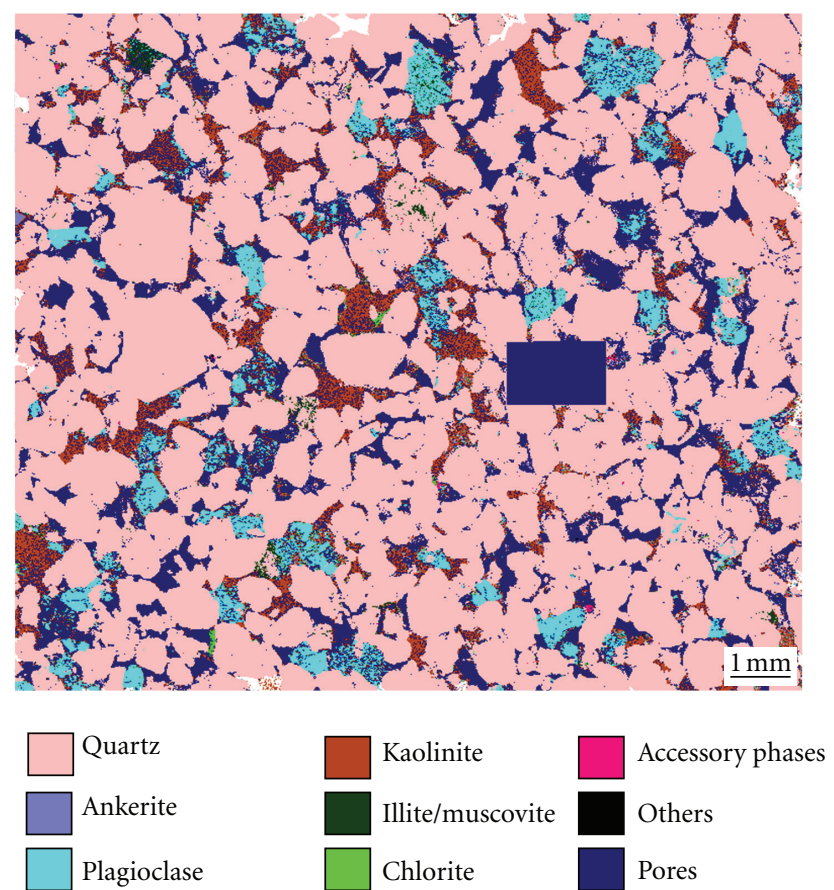

FIGURE 2: QEMSCAN image from the high-permeability zone. (The solid blue rectangle is a file conversion artifact.)

amounts of ankerite and kaolinite clay cement. This zone is more similar to the cemented zone with respect to the presence of ankerite and interstitial porosity. Much like the cemented zone, most of the porosity $(20 \%)$ is interstitial between the fine-grained kaolinite and chlorite.
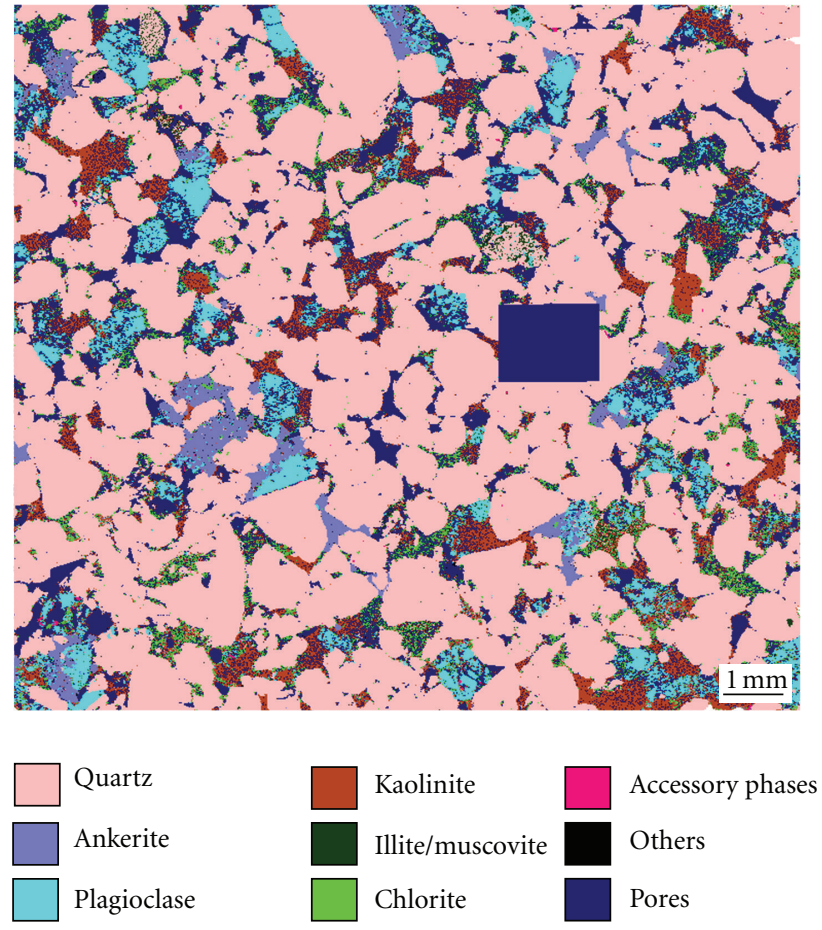

FIGURE 3: QEMSCAN image from the lower-permeability zone. (The solid blue rectangle is a file conversion artifact.)

Table 2 shows the mineral volume percentage related to each of the zones as described above.

\section{Methodology}

4.1. Experimental Description. For the laboratory core experiments, we used the direct pulse transmission technique to record compressional and shear-wave velocities at ultrasonic frequencies $(\approx 1 \mathrm{MHz})$. The experimental setup included a pressure vessel to encase and apply an isostatic confining pressure to the core sample; heat tapes wrapped around the pressure vessel to control the temperature; independent pumps for regulating confining pressure and pore pressure; a pulse generator; a digital oscilloscope for recording wave forms. A transducer was placed at each flat end of the core plug sample and was capable of recording a compressional wave and two shear waves in orthogonal directions. The two shear waves were oriented along the fast- and slowvelocity directions relative to the core sample at benchtop conditions. Each transducer casing had a fluid line for injecting the different fluids through the sample. In addition to recording the different wave modes, average axial strain was measured along the major axis of the sample. Uncertainties from the experimental setup correspond to a velocity error of $0.3 \%$ to $0.4 \%$. However, the actual error is higher due to hand-picking first arrivals.

4.2. Testing Sequence. We started the testing sequence with dry rock measurements where we incrementally increased 
TABLE 2: QEMSCAN mineral volume (\%) of the three zones.

\begin{tabular}{lccccccccc}
\hline Zone & Quartz & Ankerite & Plagioclase & Kaolinite & Illite & Chlorite & Accessory Phases & Others \\
\hline Cemented & 66 & 19 & 6 & 7 & trace & trace & trace & 1 \\
High permeability & 84 & trace & 6 & 8 & 1 & trace & trace & trace \\
Lower permeability & 75 & 4 & 8 & 8 & 1 & 3 & trace & trace \\
\hline
\end{tabular}

the confining pressure from $3.45 \mathrm{MPa}$ to $41.37 \mathrm{MPa}$ at the estimated reservoir temperature of $63.9^{\circ} \mathrm{C}$.

Following the dry rock measurements, we vacuum saturated the core sample with brine then recorded measurements at different pore pressures. The fluids flushed through the samples following brine were live oil, live oil with a $0.334 \mathrm{~mol}$ fraction of $\mathrm{CO}_{2}$, and pure $\mathrm{CO}_{2}$. The pore pressure range for the brine-saturated samples was $29.65 \mathrm{MPa}$ to 3.45 MPa, to simulate the stress path from an injection well to a production well. For the other fluids, live oil, live oil with a $0.334 \mathrm{~mol}$ fraction of $\mathrm{CO}_{2}$, and pure $\mathrm{CO}_{2}$, the pore pressure range was $29.65 \mathrm{MPa}$ to $6.89 \mathrm{MPa}$. For these fluids, we did not record data below $6.89 \mathrm{MPa}$ since these pressures would be below the bubble point. For the fluid-saturated and fluidflushed cases, a constant confining pressure of $44.82 \mathrm{MPa}$ is maintained to stimulate the stress of the overburden, and all the measurements were recorded at $63.9^{\circ} \mathrm{C}$.

4.3. Fluid Properties. The fluids used to saturate and flush through the core samples were reproduced to simulate the actual reservoir fluids at Postle Field. These fluids consist of brine with an $\mathrm{NaCl}$ concentration of $142,000 \mathrm{ppm}$, live oil with a gas oil ratio (GOR) of $103 \mathrm{~L} / \mathrm{L}$, live oil with a 0.334 mole fraction of $\mathrm{CO}_{2}$, and pure $\mathrm{CO}_{2}$. The live oil has an API gravity of 38.6 and a gas gravity of 0.786 . This information was obtained from a reservoir fluid study provided by the current field operator. Using the Fluid Acoustics for Geophysics (FLAG) calculator [11], the live oil bubble point is estimated to be $13.33 \mathrm{MPa}$ at $63.9^{\circ} \mathrm{C}$. The mixture consisting of live oil and a mole fraction of $0.334 \mathrm{CO}_{2}$ has an estimated bubble point of $17.14 \mathrm{MPa}$ at $63.9^{\circ} \mathrm{C}$. The GOR and volume of gas for the live oil with a 0.334 mole fraction of $\mathrm{CO}_{2}$ was calculated assuming a gas gravity of 1.53 and a molecular weight of $44.01 \mathrm{gm} / \mathrm{mole}$ for $\mathrm{CO}_{2}$. This approach was used by Wang et al. [35] based on experimental measurements of Postle Field oil and mixtures of approximately $10 \mathrm{~mole} \%$ and $50 \mathrm{~mole} \% \mathrm{CO}_{2}$. Figures 4 and 5 show the properties of the fluids over the pore pressure range used in the experiment calculated with the FLAG calculator [11]. The phase of $\mathrm{CO}_{2}$ for these pressures is supercritical fluid with the exception of the lowest pressure, 6.89 MPa, where $\mathrm{CO}_{2}$ is in the gas phase.

\section{Results and Discussion}

First, we measured compressional wave (P-wave) and shear wave (S-wave) velocities in air-saturated samples (dry rock) while loading and unloading an isostatic confining pressure. Following the dry rock testing, we measured P- and S-wave velocities, as a function of pore pressure, on brine-saturated

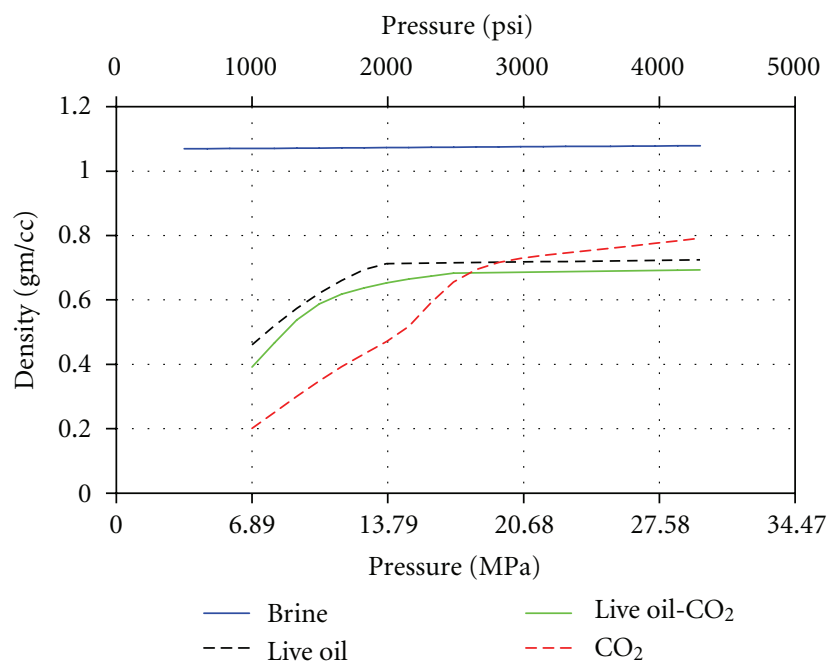

FIGURE 4: Fluid density as a function of pressure, modeled using the FLAG calculator [11].

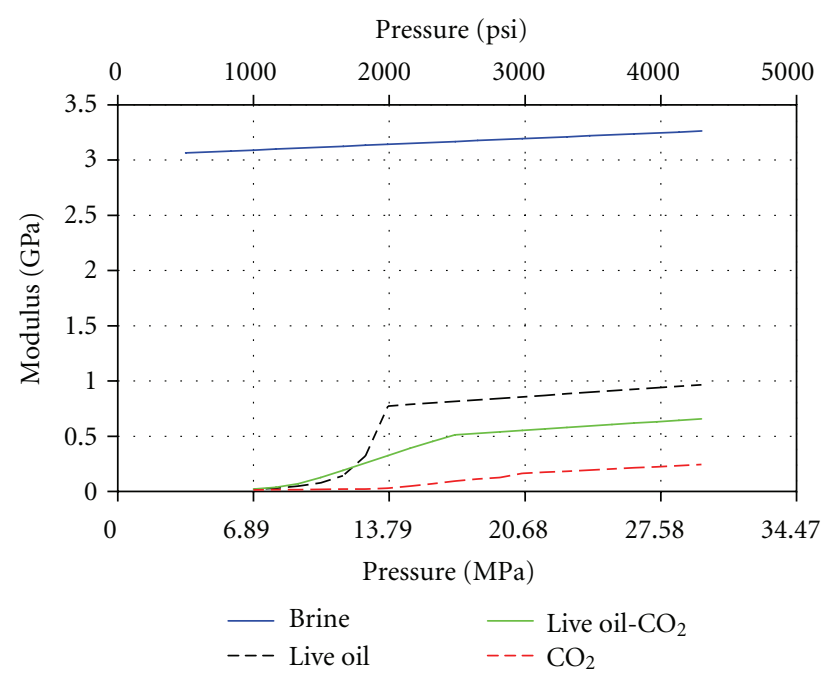

FIGURE 5: Bulk modulus of fluids as a function of pressure, modeled using the FLAG calculator [11].

core samples which were then flooded with live oil, live oil with a $0.334 \mathrm{~mol}$ fraction of $\mathrm{CO}_{2}$, and pure $\mathrm{CO}_{2}$, with a constant confining pressure of $44.82 \mathrm{MPa}$.

5.1. Core-Measured Velocities. The measured velocities, Pand S-wave, are shown in Figures 6-10 for the dry rock and fluid-saturated core samples. The S-wave velocity shown in these figures is the average of the two orthogonally measured 
TABLE 3: Percentage change of P-wave velocity with increasing differential pressure from 15.17 MPa to 37.92 MPa.

\begin{tabular}{|c|c|c|c|c|c|c|}
\hline Sample & $\begin{array}{c}\text { Dry Rock Loading } \\
(\%)\end{array}$ & $\begin{array}{c}\text { Dry Rock Unloading } \\
(\%)\end{array}$ & $\begin{array}{c}\text { Brine Sat. } \\
(\%)\end{array}$ & $\begin{array}{l}\text { Oil Flushed } \\
(\%)\end{array}$ & $\begin{array}{c}\text { Oil- } \mathrm{CO}_{2} \text { Flushed } \\
(\%)\end{array}$ & $\begin{array}{c}\mathrm{CO}_{2} \text { Flushed } \\
(\%)\end{array}$ \\
\hline Cemented & 6.5 & -3.6 & 0.94 & 2.4 & - & 3.2 \\
\hline High permeability no. 1 & 5.4 & -6.1 & 2.5 & - & -0.24 & 1.4 \\
\hline High permeability no. 2 & 8.0 & -5.1 & 2.4 & 1.8 & 4.6 & 5.9 \\
\hline Lower permeability no. 1 & 4.0 & -3.3 & 2.8 & 1.9 & 3.0 & 4.6 \\
\hline Lower permeability no. 2 & 5.4 & -4.1 & 2.9 & 2.0 & - & 3.4 \\
\hline
\end{tabular}

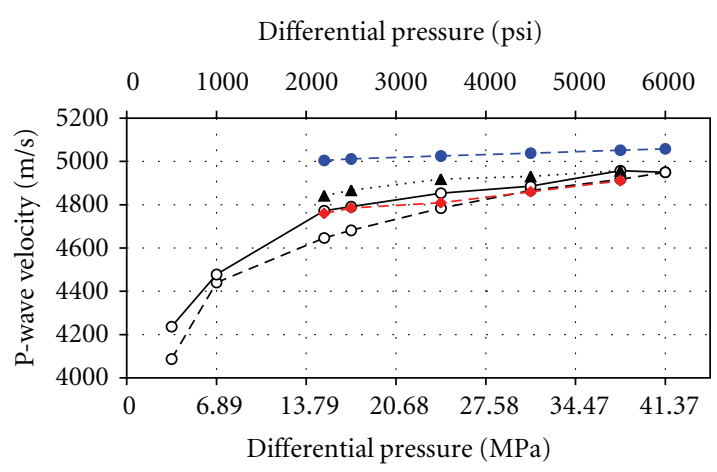

(a) P-wave velocities for the cemented sample versus differential pressure

Differential pressure (psi)

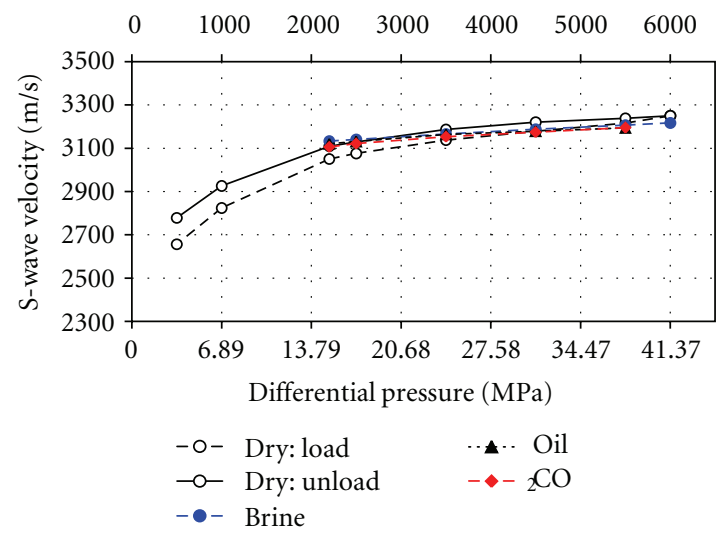

(b) S-wave velocities for the cemented sample versus differential pressure

FIGURE 6: P- and S-wave velocities for the cemented sample versus differential pressure for dry rock, brine saturated, and when flushed with live oil and $\mathrm{CO}_{2}$.

S-waves. Differential pressure, $P_{d}$, is defined as confining pressure, $P_{c}$, minus pore pressure, $P_{p}:(1)$;

$$
P_{d}=P_{c}-P_{p}
$$

In general, the high-permeability samples show a greater sensitivity to both confining pressure and pore pressure. Both P-wave and S-wave velocities decrease with decreasing differential pressure (i.e., increasing pore pressure). The Pwave velocities show a larger decrease in velocities due to pressure when flooded with $\mathrm{CO}_{2}$. Whereas pore fluid has

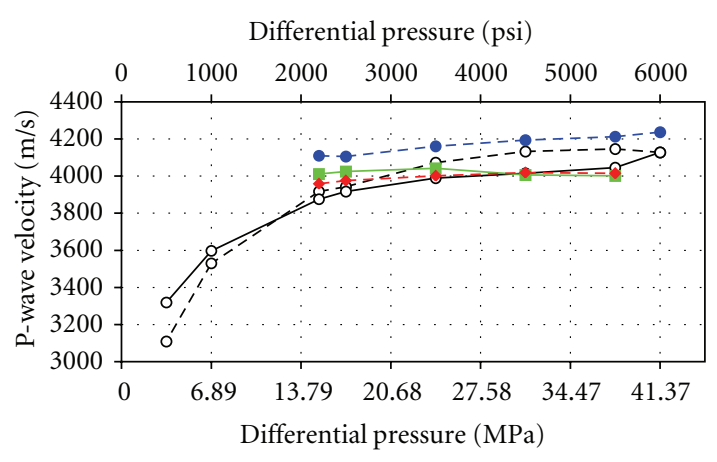

(a) P-wave velocities for the high-permeability number 1 sample versus differential pressure

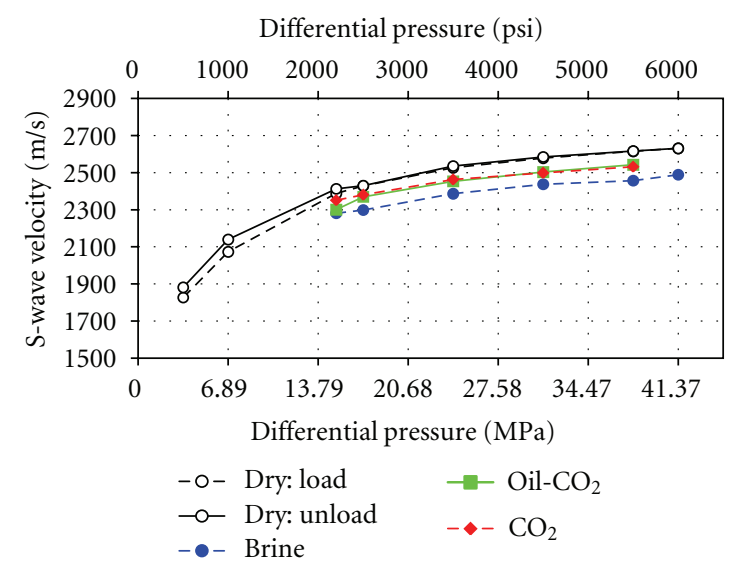

(b) S-wave velocities for the high-permeability number 1 sample versus differential pressure

FIGURE 7: P- and S-wave velocities for the high-permeability number 1 sample versus differential pressure for dry rock, brine saturated, and when flushed with the oil- $\mathrm{CO}_{2}$ mixture, and $\mathrm{CO}_{2}$.

little bearing on S-wave velocities. Tables 3 and 4 show the percentage change in velocity for dry rock and fluidsaturated core samples over the differential pressure range of 15.17 MPa to 37.92 MPa.

In terms of different lithological characteristics of the core samples with respect to velocity, the higher the permeability of the sample, the lower the P-wave and S-wave velocities. This relationship cannot be extended to porosity since the porosities of the lower-permeability samples were very to the high-permeability samples. 
TABLE 4: Percentage change of S-wave velocity with increasing differential pressure from 15.17 MPa to 37.92 MPa.

\begin{tabular}{|c|c|c|c|c|c|c|}
\hline Sample & $\begin{array}{c}\text { Dry Rock Loading } \\
(\%)\end{array}$ & $\begin{array}{c}\text { Dry Rock Unloading } \\
(\%)\end{array}$ & $\begin{array}{c}\text { Brine Sat. } \\
(\%)\end{array}$ & $\begin{array}{l}\text { Oil Flushed } \\
(\%)\end{array}$ & $\begin{array}{c}\text { Oil- } \mathrm{CO}_{2} \text { Flushed } \\
(\%)\end{array}$ & $\begin{array}{c}\mathrm{CO}_{2} \text { Flushed } \\
(\%)\end{array}$ \\
\hline Cemented & 6.5 & -4.3 & 2.3 & 2.3 & - & 2.9 \\
\hline High permeability no. 1 & 10.2 & -8.3 & 7.7 & - & 10.5 & 7.7 \\
\hline High permeability no. 2 & 8.3 & -6.4 & 8.7 & 9.7 & 10.3 & 9.1 \\
\hline Lower permeability no. 1 & 6.4 & -5.2 & 5.0 & 5.9 & 5.3 & 5.7 \\
\hline Lower permeability no. 2 & 6.9 & -5.5 & 3.4 & 3.9 & - & 4.4 \\
\hline
\end{tabular}

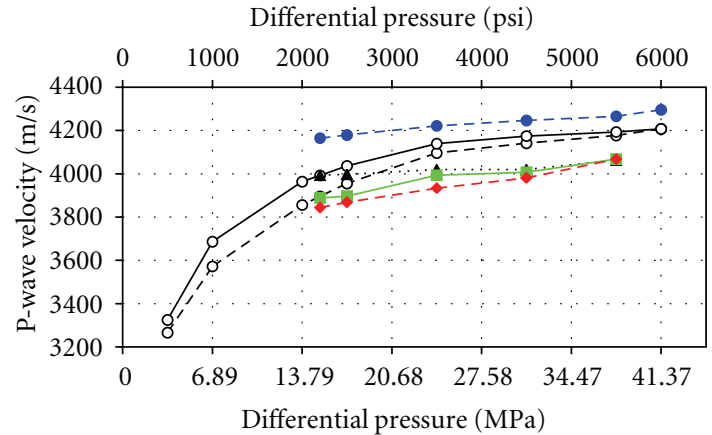

(a) P-wave velocities for the high-permeability number 2 sample versus differential pressure

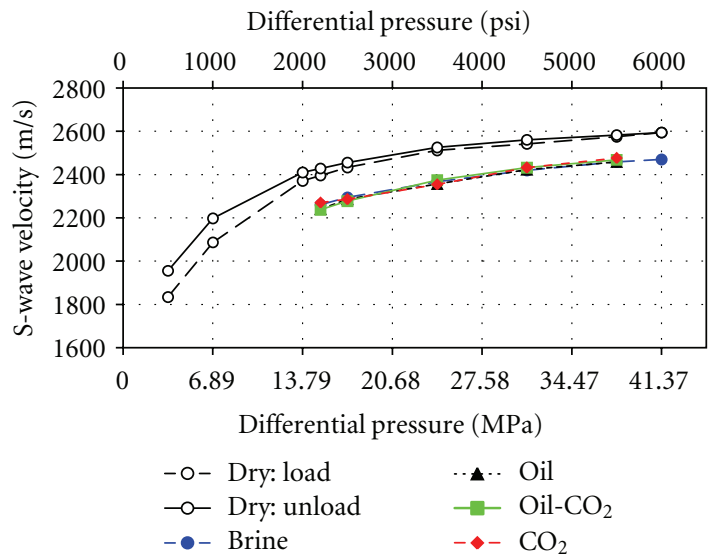

(b) S-wave velocities for the high-permeability number 2 sample versus differential pressure

FIGURE 8: P- and S-wave velocities for the high-permeability number 2 sample versus differential pressure for dry rock, brine saturated, and when flushed with live oil, the oil- $\mathrm{CO}_{2}$ mixture, and $\mathrm{CO}_{2}$.

The P-wave velocities show a response to both pressure and fluid type. The P-wave velocities systematically decrease, where brine saturated is the fastest and $\mathrm{CO}_{2}$ flushed is usually the slowest. The S-wave velocities' response is mainly dominated by pressure and generally the fluid effect is negligible.

Some specific observations with respect to each of the core samples are as follows.

5.1.1. Cemented Sample. The S-wave velocity for the brinesaturated sample has a slightly higher velocity than when

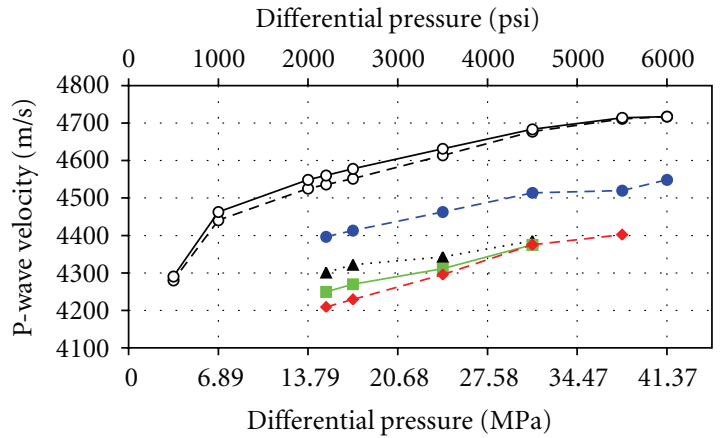

(a) P-wave velocities for the low-permeability number 1 sample versus differential pressure

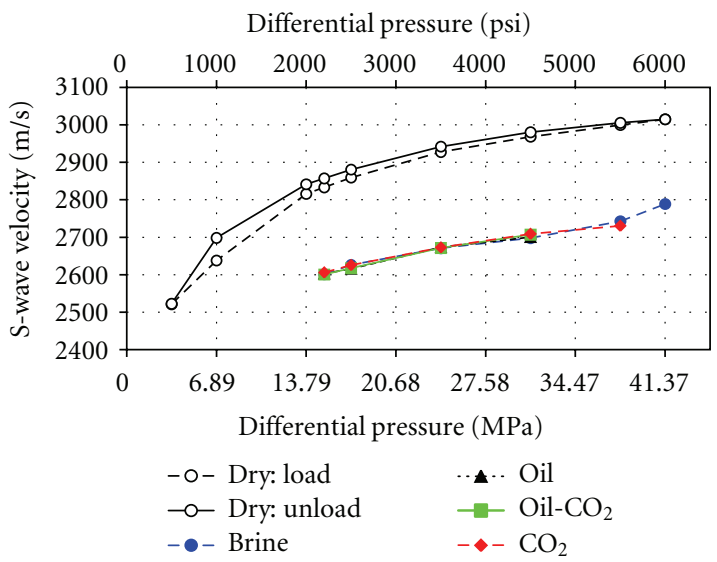

(b) S-wave velocities for the low-permeability number 1 sample versus differential pressure

FIGURE 9: P- and S-wave velocities for the low-permeability number 1 sample versus differential pressure for dry rock, brine saturated, and when flushed with live oil, the oil- $\mathrm{CO}_{2}$ mixture, and $\mathrm{CO}_{2}$. (Note dry rock velocities were recorded at $20^{\circ} \mathrm{C}$, fluid-saturated velocities were recorded at $63.9^{\circ} \mathrm{C}$.)

$\mathrm{CO}_{2}$ flushed (Figure 6(b)). More commonly the opposite behavior is observed.

5.1.2. High Permeability Number 1. The dry rock P-wave velocities (Figure 7(a)) show an unusual pattern where the velocity due to loading is higher than the velocity while unloading. This loading and unloading cycle may have caused permanent damage to the core leading to this response. Additionally, the $\mathrm{P}$-wave velocities of the mixture consisting of live oil with a mole fraction of $0.334 \mathrm{CO}_{2}$ and 


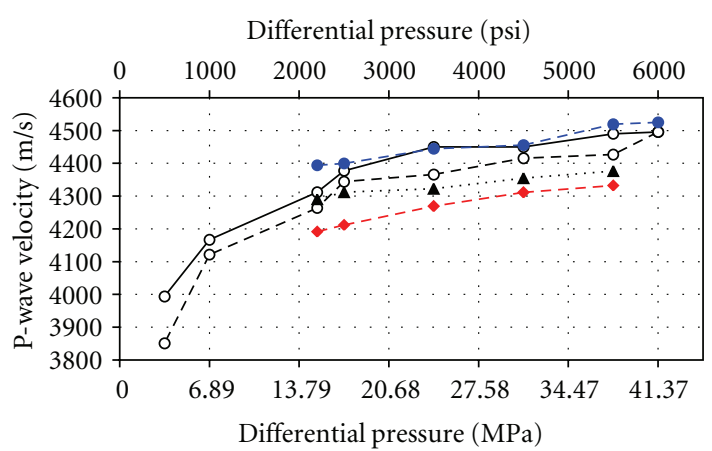

(a) P-wave velocities for the low-permeability number 2 sample versus differential pressure

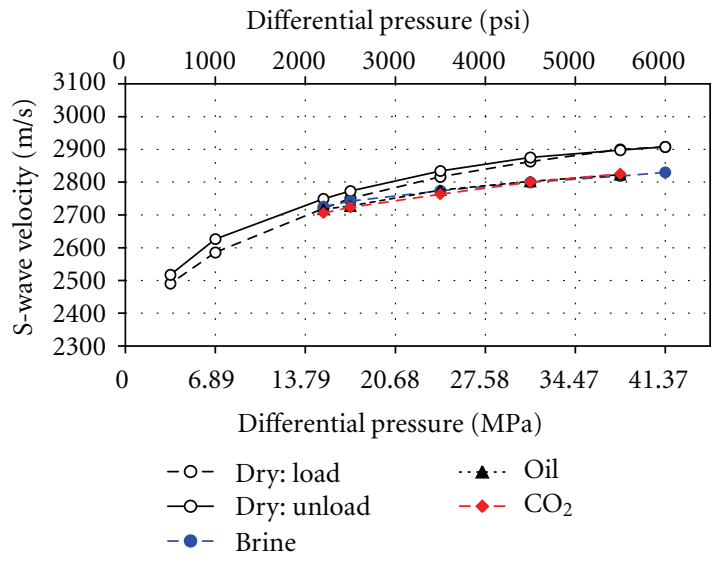

(b) S-wave velocities for the low-permeability number 2 sample versus differential pressure

Figure 10: P- and S-wave velocities for the low-permeability number 2 sample versus differential pressure for dry rock, brine saturated, and when flushed with live oil and $\mathrm{CO}_{2}$.

pure $\mathrm{CO}_{2}$ become nearly equal at a differential pressures of $31.03 \mathrm{MPa}$ and $37.92 \mathrm{MPa}$ (equivalent to pore pressures of 13.79 $\mathrm{MPa}$ and $6.89 \mathrm{MPa}$ ). The estimated bubble point for the oil- $\mathrm{CO}_{2}$ mixture is $17.14 \mathrm{MPa}$, suggesting the dominant phase of the mixture at these pressures could be gas.

In regards to the S-wave velocities (Figure 7(b)), the dry rock velocities do not show the same pattern as the P-wave velocities during the loading and unloading cycle. The dry rock S-wave velocities exhibit a response consistent with the other samples, where the velocity slightly increases during the unloading cycle. This sample showed the most S-wave velocity response to fluid; where the brine-saturated velocity is slower than when flushed with the oil- $\mathrm{CO}_{2}$ mixture and $\mathrm{CO}_{2}$.

5.1.3. High Permeability Number 2. Much like the highpermeability number 1 sample, the high-permeability number 2 sample (Figure 8(a)) shows a very similar P-wave velocity response to live oil with a mole fraction of $0.334 \mathrm{CO}_{2}$ and pure $\mathrm{CO}_{2}$. These velocities nearly converge at differential pressures of $31.03 \mathrm{MPa}$ and $37.92 \mathrm{MPa}$. Also, the velocity of the sample when flushed with live oil begins to converge with the oil- $\mathrm{CO}_{2}$ mixture and $\mathrm{CO}_{2}$ at differential pressures

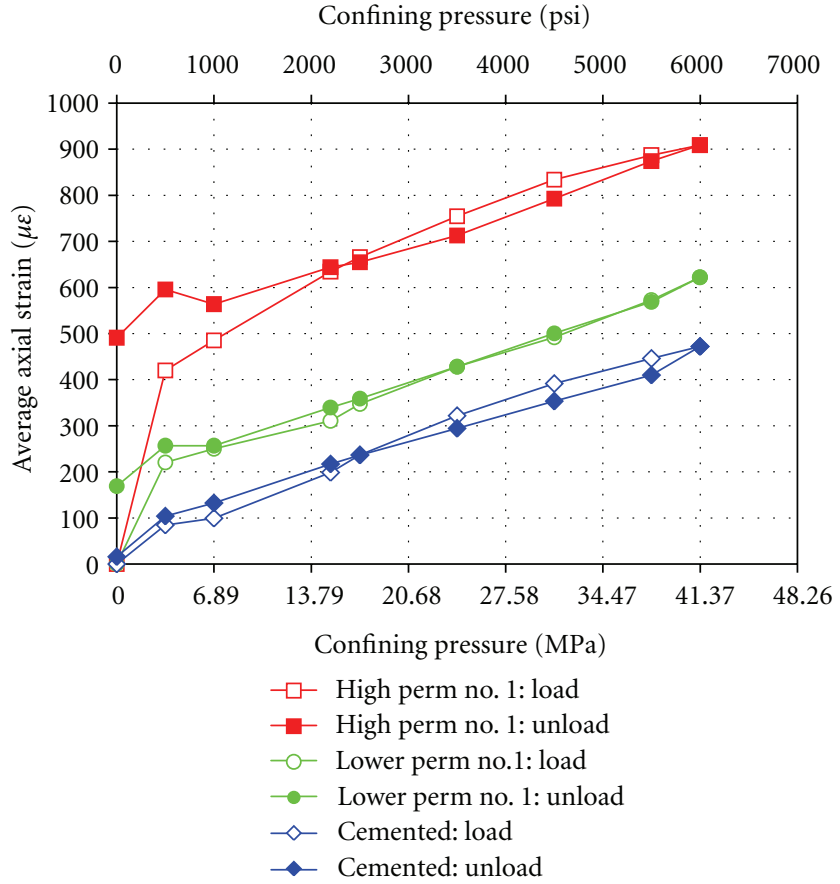

Figure 11: Average axial strain as a function of isostatic confining pressure for three dry rock core samples.

of $31.03 \mathrm{MPa}$ and above. Again, this is most likely due to the effect of gas coming out of solution (live oil has a bubble point estimated to be $13.33 \mathrm{MPa}$ at $63.9^{\circ} \mathrm{C}$ ).

5.1.4. Low Permeability Number 1. The most obvious difference between the low-permeability number 1 sample and the other core samples is the much higher dry rock velocity for both P- and S-waves when compared to the fluid-saturated and fluid-flushed velocities (Figure 9). These higher dry rock velocities are the result of being recorded at $20^{\circ} \mathrm{C}$, while the fluid measurements were recorded at the estimated reservoir temperature of $63.9^{\circ} \mathrm{C}$.

5.1.5. Low Permeability Number 2. The low-permeability number 2 sample S-wave velocities (Figure 10(b)) show a similar trend as the cemented sample where the brinesaturated velocity is at some pressures marginally higher than when the sample was flushed with live oil and $\mathrm{CO}_{2}$. Again, typically the opposite effect is observed.

5.2. Average Axial Strain. Average axial strains measured during the dry rock loading and unloading cycle for three samples, each from a different lithological zone, are shown in Figure 11. The isostatic confining pressure has a greater effect on the high-permeability sample and least affects the cemented sample. We used these results to correct for sample length, porosity, and density at each differential pressure.

5.3. Log Facies Model. One method to link the core sample information to well log response is through log facies modeling. We generated a log facies model using 12 wells 

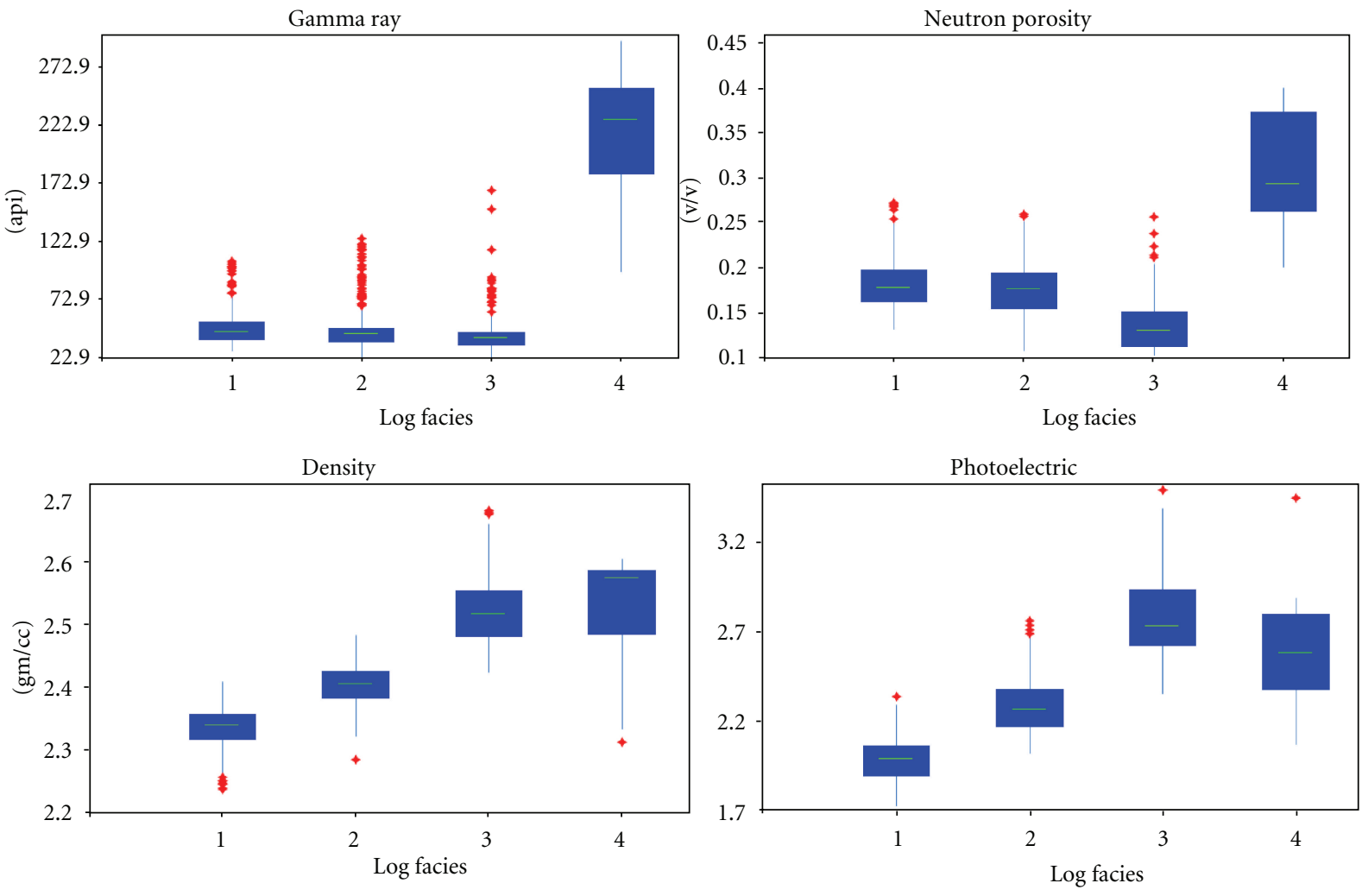

1: High-quality reservoir $\quad 2:$ Intermediate-quality reservoir

3: Low-quality reservoir

4: Interbedded shale

FIGURE 12: Box and whisker plot of the four clusters for the input logs used to generate the log facies model.

logged with the same technology within Postle Field. These well logs were corrected for environmental effects related to pressure, temperature, and borehole diameter. The well logs used as inputs for the log facies model were gamma ray, neutron porosity, bulk density, and photoelectric logs. The reservoir zones from each well log were spliced together in series to capture the variability of the reservoir. To identify the different log responses within the reservoir zone, principal component analysis was applied to maximize variability followed by cluster analysis to group data by similar log response. Figure 12 shows the box and whisker plot for each of the four clusters and the log response associated with each cluster. For each box, the central green line is the median of the data, the edges of the box are the 25th and 75th percentiles, and vertical lines (whiskers) extend to the extreme data points not considered outliers, the outliers are plotted as red diamonds. Based on the trends of the four box and whisker plots for each log response, log facies number 1 is interpreted as high-quality reservoir, log facies number 2 as intermediate-quality reservoir, log facies number 3 as low-quality reservoir, and log facies number 4 represents an interbedded shale.

Once the log facies are established, a supervised classification method is then applied to wells with additional data such as sonic or core data. This is shown in Figure 13 where the log facies model has been applied to a well with coremeasured porosity and permeability. From Figure 13, an inference can be made that the dark blue log facies (number 1) relates to high-permeability zones, the light blue log facies (number 2) correlates to intermediate-permeability zones, and the green log facies (number 3 ) corresponds to zones of low permeability.

Unfortunately, the well which the core samples used for the laboratory velocity measurements did not have the necessary input logs for supervised classification. To relate the core samples to the log facies model, we compared the permeability of the core samples to the permeability associated with each log facies taken from the well in Figure 13. Figure 14 shows this comparison where the core samples used in the laboratory velocity measurements are shown as stars and each box and whisker plot represents the variability in permeability for each of the reservoir log facies. This assumes each core sample used in the laboratory velocity measurements corresponds to a log facies. Hence, the cemented sample is associated with the low-quality reservoir log facies, the high-permeability number 1 and number 2 samples are related to the high-quality log facies and the lower-permeability number 1 and number 2 samples correspond to the intermediate-quality log facies.

\subsubsection{Integrating the Log Facies Model and Core-Measured} Velocity. We achieved only limited success using Gassmann's relation [9] and the effective medium theory of Mori and Tanaka $[36,37]$ to predict velocity changes related to fluid 


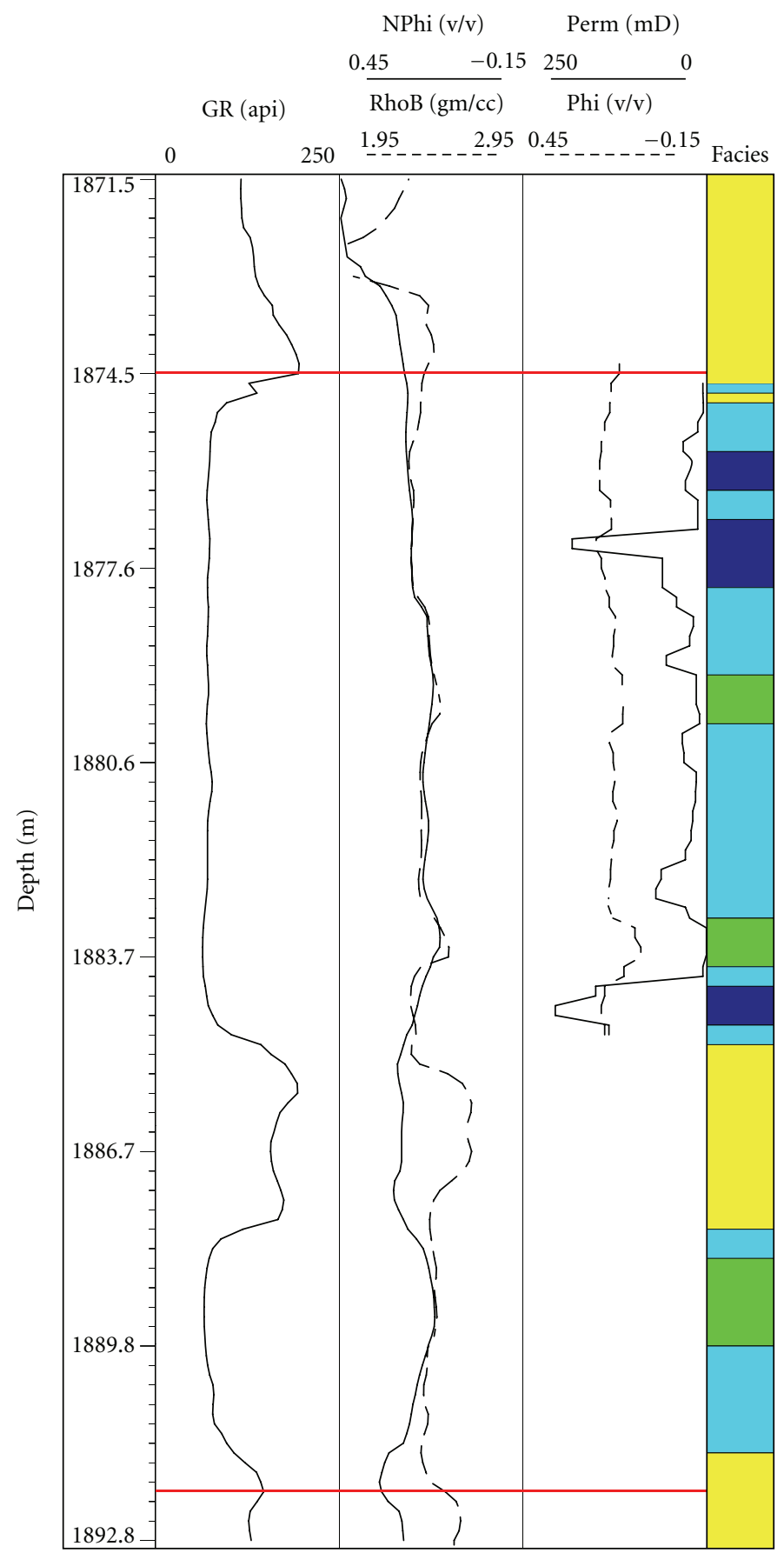

Log facies

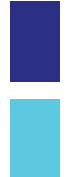

1: High-quality reservoir

3: Low-quality

reservoir

2: Intermediate-

quality reservoir

4: shale

FIGURE 13: Log facies model applied to a well with core-measured porosity and permeability. The first track shows the gamma ray log. Track 2 plots the neutron porosity and bulk density. Track 3 represents core-measured permeability and porosity. The reservoir zone (Morrow A sandstone) is shown between the horizontal red lines. 


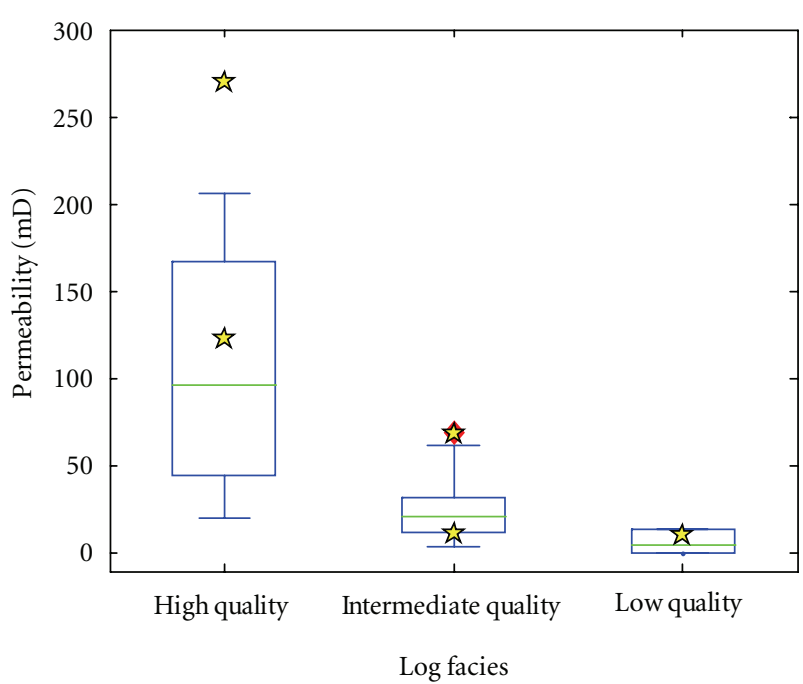

Figure 14: Permeability of the core samples used in the laboratory velocity measurements (stars) superimposed on the box and whisker plot of the permeability related to each log facies (from the well in Figure 13).

saturation and differential pressure in the core samples. Generally, Gassmann's relation is not expected to model fluid effects at ultrasonic frequencies. This result only means Gassmann's relation is not appropriate for this laboratory data but may be suitable at the field scale [38]. Therefore, we apply an alternative approach which assumes a direct relationship between the log facies model and the core-measured velocities. This direct relationship is based on estimating the reservoir condition in the laboratory velocity measurements, then applying the changes associated with fluid type and pressure observed in the laboratory measurements directly to the only cross-dipole velocity well logs recorded in the Postle Field study area.

The reservoir condition from petrophysical analysis estimates a water saturation of $45 \%$ [34]. Figure 15 shows the properties of live oil, brine, and the reservoir condition with a water saturation of $45 \%$. To estimate the reservoir condition the difference in velocity between oil and brine is taken and is $76 \%$ less than the velocity of brine.

This estimated velocity at reservoir conditions now allows for changes to be applied to the log response based on laboratory velocity measurements made on the core samples. For example, to estimate the log response at complete brine saturation, the log would be multiplied by the percent change between brine-saturated velocity and the estimated reservoir velocity from the experimental core measurement.

Since very little fluid effect is observed in the S-wave velocity core measurements, it is assumed that the fluid effect is negligible and the only changes in S-wave velocity are due to pressure. For estimating changes in the S-wave log response, the $\mathrm{S}$-wave velocity is multiplied by the percent change from the reservoir condition to the desired pore pressure.

The core samples we selected to estimate the changes in $\mathrm{P}$ - and S-wave velocity log response were the cemented
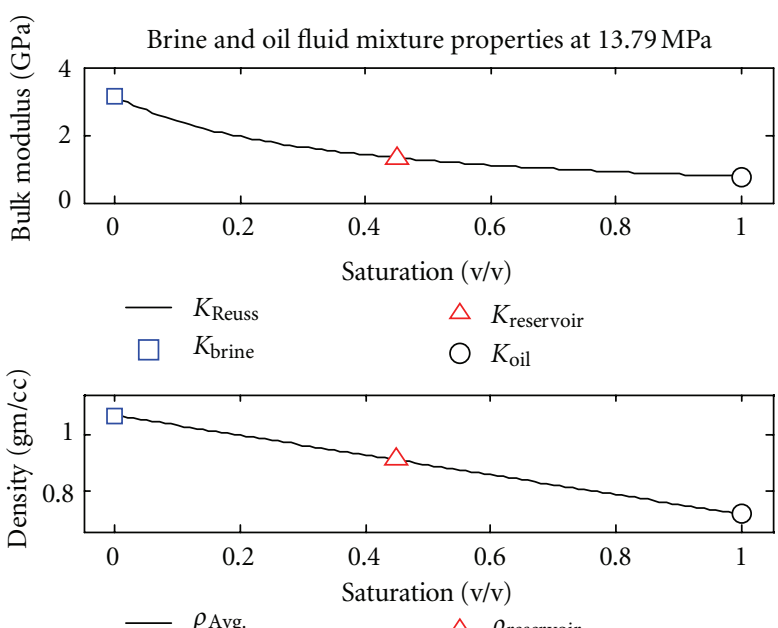

$\begin{array}{lll}\square & \rho_{\text {Avg. }} & \Delta \rho_{\text {reservoir }} \\ \square & \rho_{\text {brine }} & \bigcirc \rho_{\text {oil }}\end{array}$

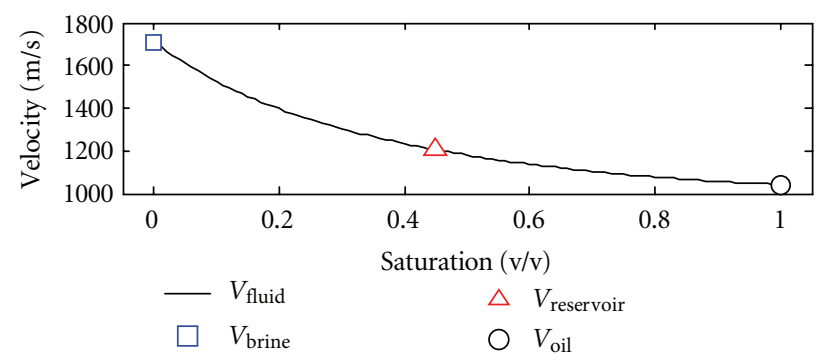

Figure 15: Calculated fluid properties at reservoir conditions for live oil, brine, and a mixture with a brine saturation of $45 \%$.

sample which is associated to the low-quality reservoir log facies, the high-permeability sample number 2 which is associated to the high-quality reservoir log facies, and the lower-permeability sample number 2 which is associated to the intermediate-quality reservoir log facies. Changes in bulk density were calculated using the density transformation equation (2) where $\rho_{2}$ is bulk density saturated with the new fluid, $\rho_{1}$ is the initial bulk density, $\rho_{f 1}$ is the density of the initial fluid, and $\rho_{f 2}$ is the density of the new fluid:

$$
\rho_{2}=\rho_{1}+\phi\left(\rho_{f 1}-\rho_{f 2}\right) \text {. }
$$

Figure 16 shows the changes in log response for the conditions of complete brine saturation at pore pressures of 6.89 MPa and 29.65 MPa. Figure 17 shows the changes in log response for the conditions of complete $\mathrm{CO}_{2}$ saturation for pore pressures of $6.89 \mathrm{MPa}$ and $29.65 \mathrm{MPa}$.

5.4. Time-Lapse Amplitude Difference. We generated synthetic seismic gathers using the full waveform modeling method described in Singh and Davis [39]. To understand the $\mathrm{P}$ - and S-wave response at the Morrow A sandstone level, we created $1 \mathrm{D}$ models for the brine- and $\mathrm{CO}_{2}$-saturated cases using the modified well logs (Figures 16 and 17). The logs were blocked at $1.5 \mathrm{~m}$ and simplified to have three main reflectors: the Atoka limestone above the reservoir, the Morrow A sandstone (reservoir), and a limestone layer below the reservoir. Above the Atoka limestone, the log response was smoothed to remove the effect of multiples. 


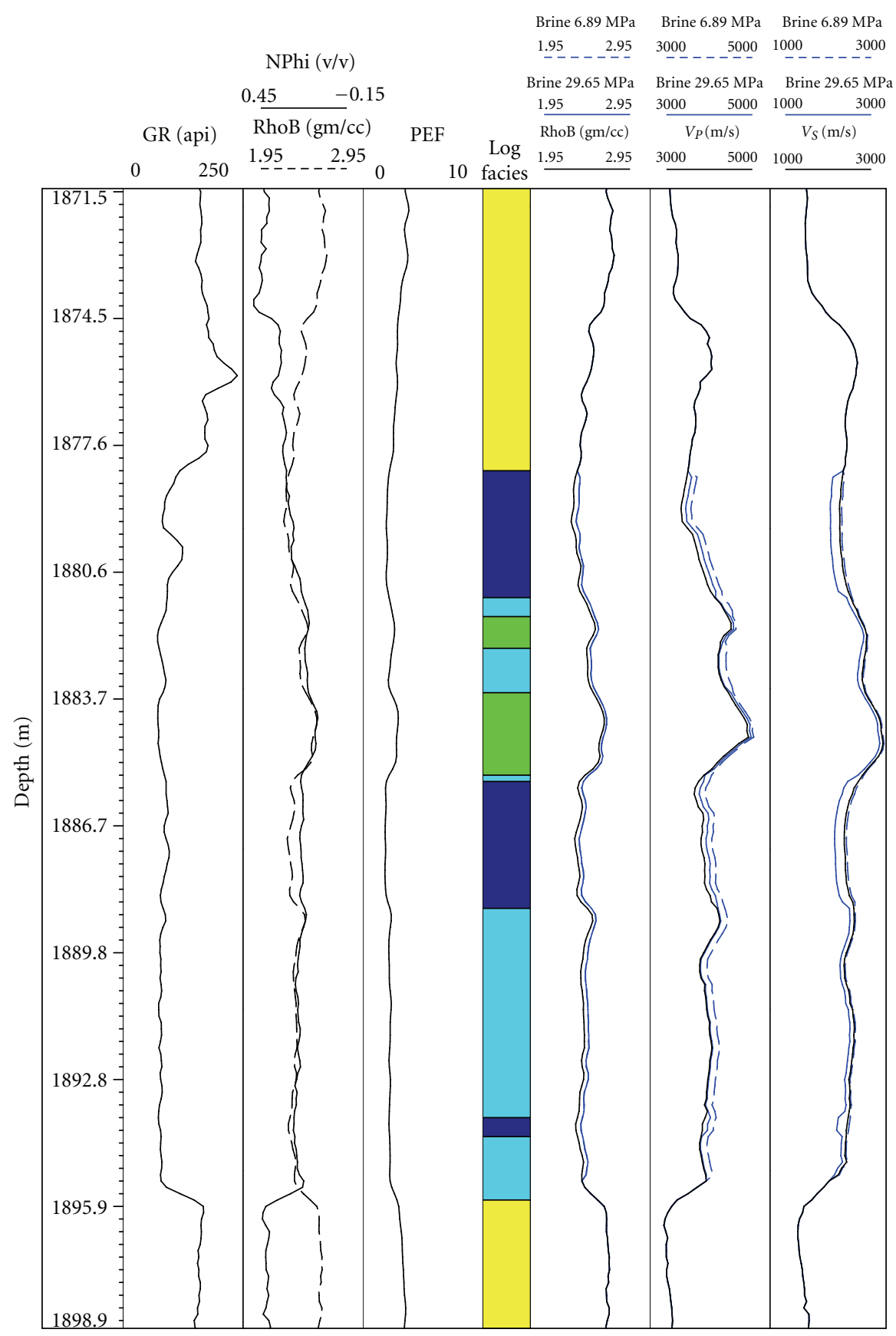

Figure 16: Estimated changes in the Morrow A sandstone for P-wave velocity, S-wave velocity, and bulk density log response for conditions of complete brine saturation at pore pressures of 6.89 MPa (blue dashed lines) and 29.65 MPa (solid blue lines). The recorded in-situ P-wave velocity, S-wave velocity, and bulk density logs are shown in black.

From the 1D models, we generated 2D multicomponent gathers simulating vertical and horizontal sources, and receivers with vertical and horizontal components. We extracted statistical wavelets from the processed P- and S-wave seismic volumes recorded at Postle Field for use in the full waveform modeling. The P-wave wavelet was zero phase with a peak frequency of $18 \mathrm{~Hz}$ and the Swave wavelet was also zero phase with a peak frequency of $13 \mathrm{~Hz}$. The gathers (Figure 18) are modeled with a maximum offset of $1829 \mathrm{~m}$, which is consistent with the usable offset from the seismic data recorded at Postle Field.

Seismic acquisition parameters and examples of $\mathrm{P}$ - and S-wave seismic data recorded at Postle Field can be found in Singh and Davis [39]. Using nearly identical wavelets and the same cross-dipole sonic logs used in this study, Singh and Davis [39] also address the tuning and interference effect at the Morrow A sandstone level. 


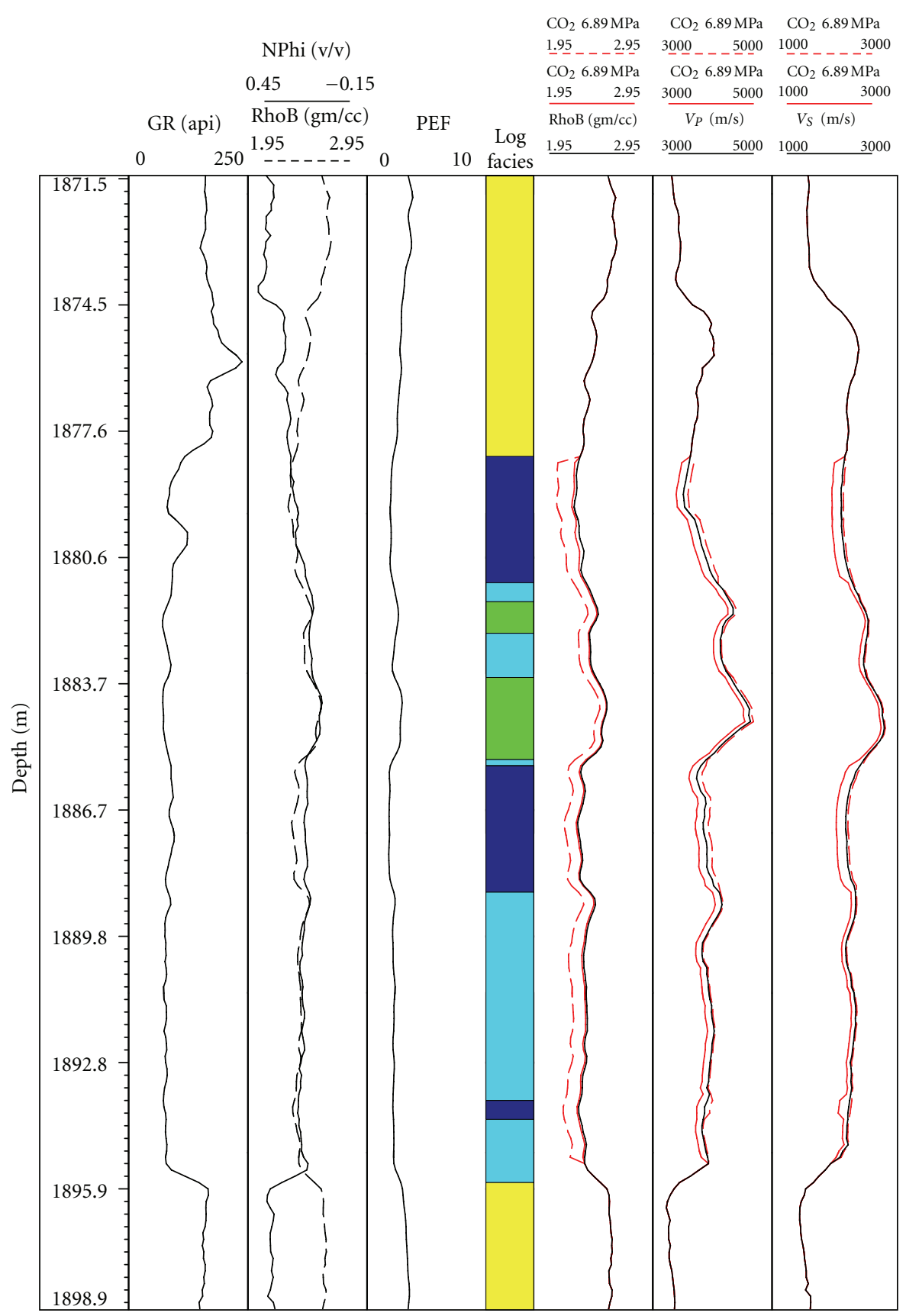

Figure 17: Estimated changes in the Morrow A sandstone for P-wave velocity, S-wave v.elocity, and bulk density log response for conditions of complete $\mathrm{CO}_{2}$ saturation at pore pressures of 6.89 MPa (red dashed lines) and 29.65 MPa (solid red lines). The recorded in-situ P-wave velocity, S-wave velocity, and bulk density logs are shown in black.

To evaluate the changes in seismic response, we analyzed the amplitude difference of the P- and S-wave gathers for the brine- and $\mathrm{CO}_{2}$-saturated cases. The amplitude difference for the brine-saturated case represents a pore pressure increase from $6.89 \mathrm{MPa}$ to $29.65 \mathrm{MPa}$ in the Morrow A sandstone. Similarly, the amplitude difference for the $\mathrm{CO}_{2}$-saturated case represents a pore pressure increase from $6.89 \mathrm{MPa}$ to 29.65 MPa in the Morrow A sandstone. The time shift for the brine and $\mathrm{CO}_{2}$ cases was minor, calculated to be less than 0.5 milliseconds. The P-wave amplitude differences are shown in
Figure 19 and the S-wave amplitude differences are shown in Figure 20.

For both the brine and $\mathrm{CO}_{2}$ cases, the $\mathrm{P}$-wave modeling shows a negative amplitude difference for an increase in pressure (Figure 19), this occurs because an increase in pore pressure results in a lower acoustic impedance. For both cases, the amplitude difference is greatest at zero offset and becomes less with increasing offset. The brine-saturated case shows a large amplitude difference starting from the reflection at the Morrow A sandstone level. The $\mathrm{CO}_{2}$ case 


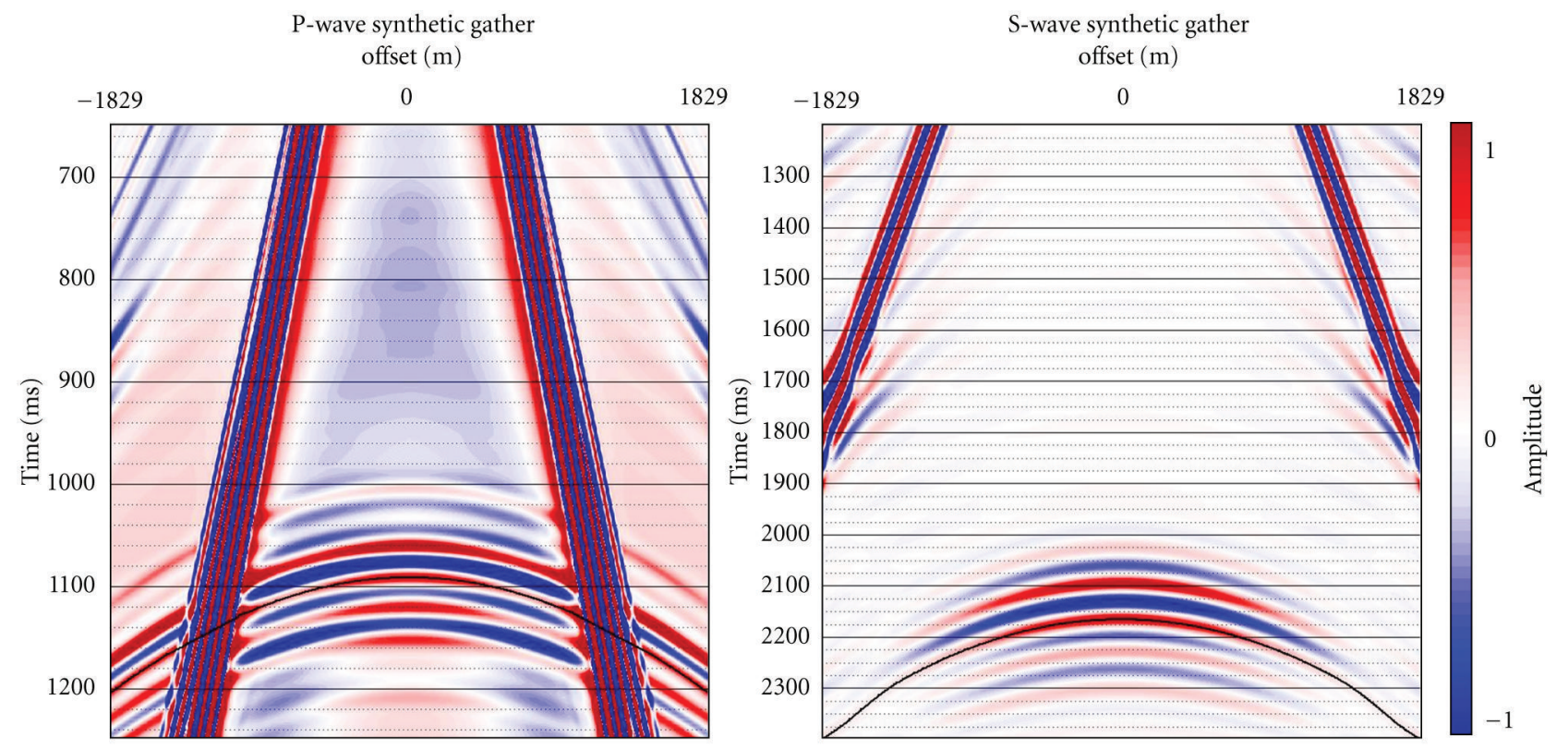

FIGURE 18: Full waveform synthetic gathers for P-wave (left) and S-wave (right) reflectivity. The Morrow A sandstone top is indicated by the black curve.

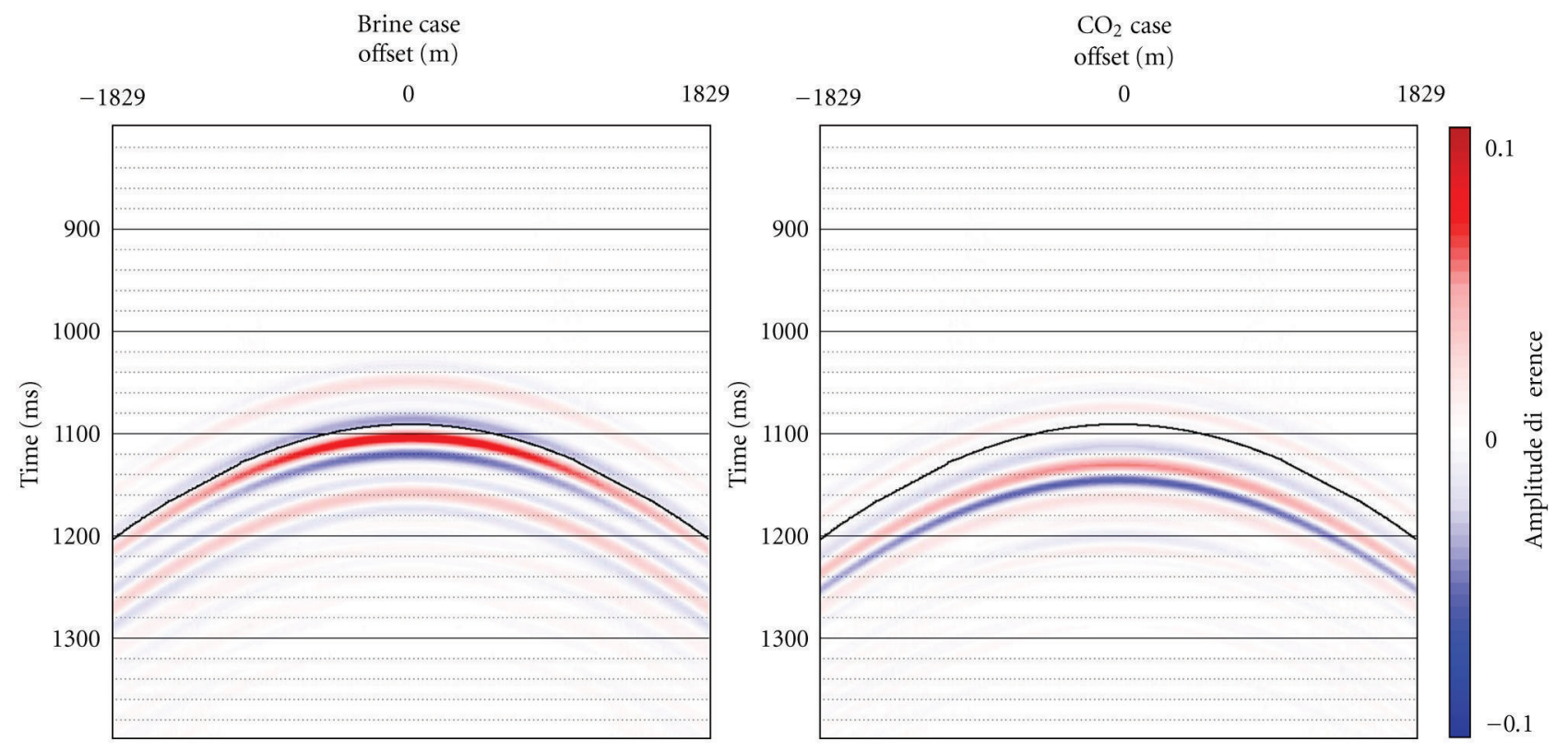

Figure 19: Comparison of the P-wave amplitude difference for the brine- and $\mathrm{CO}_{2}$-saturated cases with a pore pressure increase from 6.89 MPa to 29.65 MPa. The Morrow A sandstone top is indicated by the black curve.

shows a very weak amplitude decrease at the Morrow A sandstone reflection and a larger amplitude difference from the reflectors below the Morrow A sandstone. A change in waveform around the Morrow A sandstone for the $\mathrm{CO}_{2}$ case affects the signature of the amplitude difference. These observations suggest near-angle P-wave stacks would be better suited for time-lapse analysis with larger amplitude differences occurring below the reservoir.
Increasing pore pressure lowers the elastic impedance and hence the S-wave amplitude difference is negative with increasing pore pressure for both the brine and $\mathrm{CO}_{2}$ cases (Figure 20). The most notable observation is the amplitude difference with increasing offset between the two cases. The amplitude difference is highest at zero offset for the brinesaturated case and decreases with increasing offset. However, the $\mathrm{CO}_{2}$-saturated case shows the amplitude difference to 


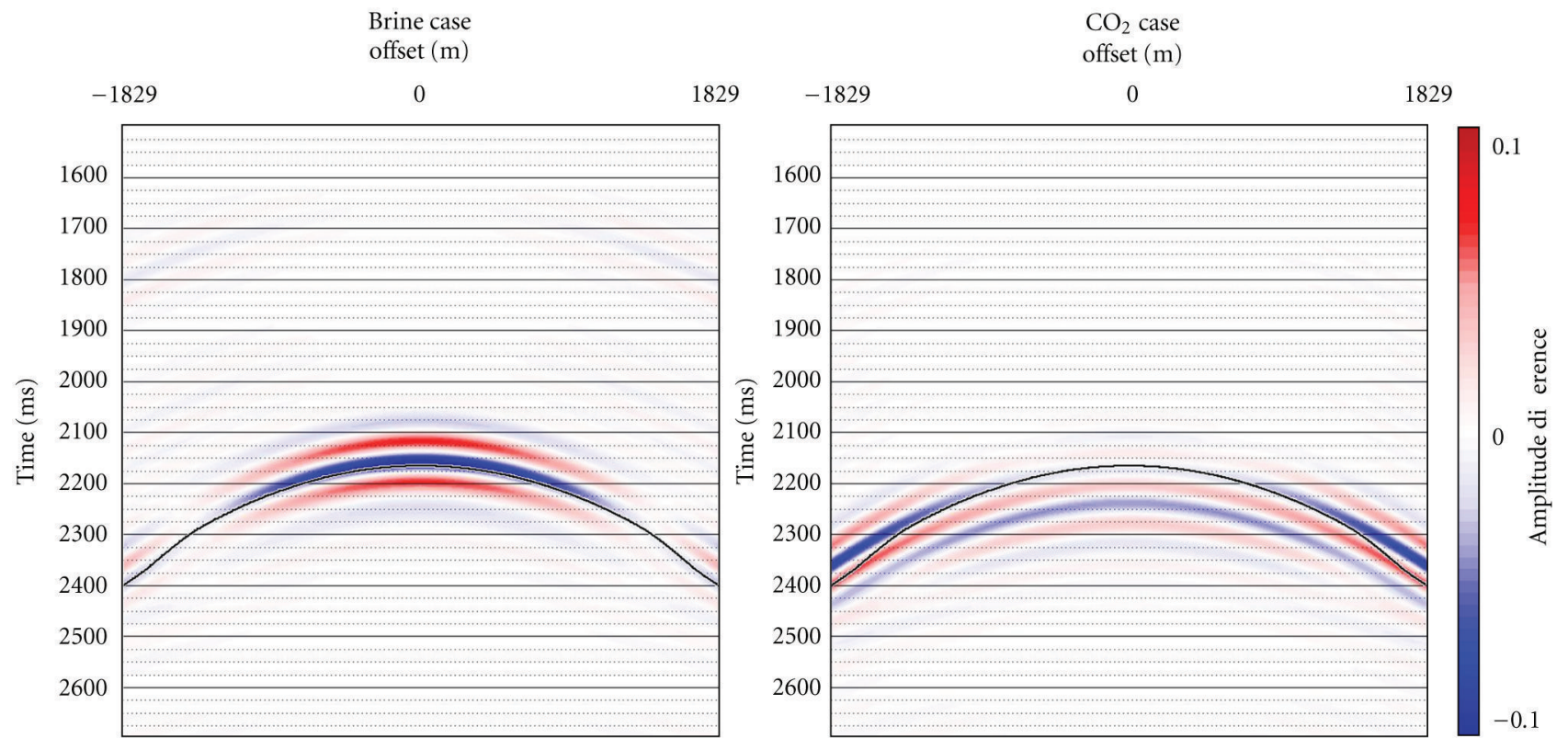

Figure 20: Comparison of the S-wave amplitude difference for the brine- and $\mathrm{CO}_{2}$-saturated cases with a pore pressure increase from 6.89 MPa to 29.65 MPa. The Morrow A sandstone top is indicated by the black curve.

increase with increasing offset. Analysis on S-wave angle stacks, rather than full offset stacks, may be more effective in detecting changes in saturation and, therefore, useful for $\mathrm{CO}_{2}$ monitoring.

The amplitude difference of the full waveform seismic modeling shows the effects fluid saturation and pressure have on $\mathrm{P}$ - and S-wave reflections. P-wave reflections show the near offsets to have the most amplitude difference. While Swave reflections show a maximum amplitude difference at near offsets for the brine case and at far offsets for the $\mathrm{CO}_{2}$ case. Also, the S-wave amplitude difference is greater than the $\mathrm{P}$-wave amplitude difference for these two cases.

To determine if the time-lapse changes are mainly due to time shift or only an amplitude difference, we compared the root mean square (RMS) amplitude difference for the two cases. Since we did not take into account any time shift when we differenced the modeled synthetic seismic gathers, representing the minimum and maximum pressures for the brine and $\mathrm{CO}_{2}$ cases (Figures 19 and 20), we calculated the RMS amplitude difference at the Morrow A sandstone top. We examined a $20 \mathrm{~ms}$ window centered at the Morrow A sandstone top for the P-wave gathers and a $40 \mathrm{~ms}$ window for the $\mathrm{S}$-wave gathers. These RMS amplitude differences are shown in Figure 21 for both the brine and $\mathrm{CO}_{2}$ cases. We observe that the RMS amplitude difference at the Morrow A top is comparable to the amplitude difference of the synthetic gathers shown in Figures 19 and 20. The RMS amplitude difference with offset also agrees with the amplitude difference of the synthetic gathers. A comparison of the RMS amplitude difference and the differenced synthetic seismic gathers demonstrate that the effect of time shift is almost negligible at the Morrow A top. The time-lapse changes at the Morrow A top (observed in Figures 19 and 20) are mainly due to amplitude differences. Figure 21 also confirms that
S-wave gathers show a larger time-lapse change as compared to the P-wave gathers.

\section{Conclusions}

Laboratory core measurements show the effects of differential pressure and fluid saturation through the P- and Swave velocity response of five Morrow A sandstone samples. The samples were saturated with brine and flushed with live oil, an oil- $\mathrm{CO}_{2}$ mixture, and pure $\mathrm{CO}_{2}$. The P-wave velocity shows a sensitivity to both fluid saturation and pressure. Whilst the S-wave velocity shows a dependence to changes in differential and a nearly negligible sensitivity to fluid saturation. Core samples taken from the high-permeability zone show the most velocity change to confining pressure and pore pressure. The core sample from the cemented zone shows the least amount of velocity change to confining pressure and pore pressure. The overall velocity decrease was greater for S-waves as shown in Tables 3 and 4. Average axial strain also showed the high-permeability sample to be the most stress-sensitive and the cemented sample the least sensitive to confining pressure.

We attempted modeling the core-measured velocities using Gassmann's relation [9] and the effective medium theory of Mori and Tanaka [36, 37]. Neither of these models successfully predicted the measured P-wave or S-wave velocities. The $\mathrm{P}$ - and S-wave velocity well logs were modified to estimate changes due to pressure and fluid saturation based on the laboratory core-measured velocities. This approximation was implemented through a log facies model where each log facies was associated with a core sample.

The P-wave amplitude difference for the brine- and $\mathrm{CO}_{2}$ saturated cases, modeling a pore pressure increase from 6.89 $\mathrm{MPa}$ to $29.65 \mathrm{MPa}$, displayed a maximum amplitude 


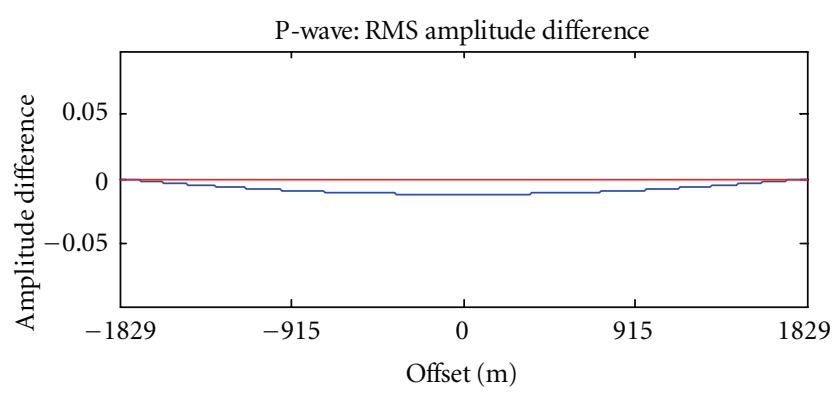

S-wave: RMS amplitude difference

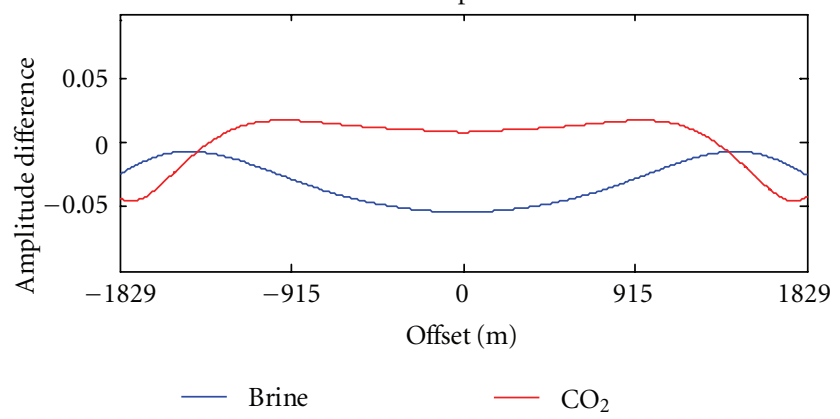

Figure 21: RMS amplitude difference at the Morrow A sandstone top for the synthetic seismic modeling of the P- and S-wave gathers.

difference at the near offsets. Whereas the S-wave shows a maximum amplitude difference at the near offsets for the brine case and a maximum amplitude difference at far offsets for the $\mathrm{CO}_{2}$ case.

The full waveform modeling results show how fluid and pressure changes in the Morrow A sandstone reservoir affect the characteristics of $\mathrm{P}$ - and $\mathrm{S}$-wave amplitude differences. In addition, the full waveform modeling shows an advantage to using angle-limited stacks as compared to full offset stacks for time-lapse analysis. These results demonstrate the benefit and establish motivation for using $\mathrm{S}$-wave seismic data in time-lapse studies involving changes in pressure and fluid saturation.

\section{Acknowledgments}

The authors would like to thank the sponsors of The Reservoir Characterization Project at Colorado School of Mines, specifically Whiting Petroleum: the current operator of Postle Field; the Center for Rock Abuse at Colorado School of Mines for the use of their Rock Squeezing Laboratory, especially Professor Michael Batzle and Weiping Wang; Tom R. Bratton for his help and guidance generating the log facies model; BP America for the use of the seismic modeling code. A. V. Wondler would like to thank BP for the BP Colorado School of Mines Ph.D. Fellowship.

\section{References}

[1] L. Kootungal, "2010 world wide EOR survey," Oil and Gas Journal, vol. 108, no. 14, pp. 41-53, 2010.
[2] A. Tura and D. Lumley, "Estimating pressure and saturation changes from time-lapse AVO data," in the 69th Annual International Meeting, SEG, Expanded Abstracts, pp. 1655-1658, 1999.

[3] M. Landrø, "Discrimination between pressure and fluid saturation changes from time-lapse seismic data," Geophysics, vol. 66, no. 3, pp. 836-844, 2001.

[4] T. L. Davis, M. J. Terrell, R. D. Benson, R. Cardona, R. R. Kendall, and R. Winarsky, "Multicomponent seismic characterization and monitoring of the $\mathrm{CO}_{2}$ flood at Weyburn Field, Saskatchewan," Leading Edge, vol. 22, no. 7, pp. 696-697, 2003.

[5] R. J. Pawar, N. R. Warpinski, J. C. Lorenz et al., "Overview of a $\mathrm{CO}_{2}$ sequestration field test in the West Perl Queen reservoir, New Mexico," Environmental Geosciences, vol. 13, no. 3, pp. 163-180, 2006.

[6] A. Robinson and T. L. Davis, "Improving efficiency of $\mathrm{CO}_{2}$ sequestration using short-term seismic monitoring: Applications from the Postle field EOR programme," First Break, vol. 29, no. 1, pp. 75-78, 2011.

[7] A. Nur and Z. Wang, Eds., Seismic and Acoustic Velocities in Reservoir Rocks, Experimental Studies, vol. 1, chapter 1, Society of Exploration Geophysicists, 1998.

[8] Z. Xue, T. Ohsumi, and H. Koide, "An experimental study on seismic monitoring of a $\mathrm{CO}_{2}$ flooding in two sandstones," Energy, vol. 30, no. 11-12, pp. 2352-2359, 2005.

[9] F. Gassmann, "Uber die elastizitat poroser medien," Vierteljahrsschrift der Naturforschenden Gesellschaft in Zrich, vol. 96, pp. 1-23, 1951.

[10] G. T. Kuster and M. N. Toksoz, "Velocity and attenuation of seismic waves in two-phase media: Part I. Theoretical formulations," Geophysics, vol. 39, no. 5, pp. 587-606, 1974.

[11] "Fluid Acoustics for Geophysics calculator," Rock Physics Lab, University of Houston and Center for Rock Abuse, Colorado School of Mines, 2009.

[12] M. King, "Wave velocities in rocks as a function of changes in overburden pressure and pore fluid saturants," Geophysics, vol. 31, pp. 50-73, 1966.

[13] S. N. Domenico, "Rock lithology and porosity determination from shear and compressional wave velocity," Geophysics, vol. 49, no. 8, pp. 1188-1195, 1984.

[14] Z. Xue and T. Ohsumi, "Seismic wave monitoring of $\mathrm{CO}_{2}$ migration in water-saturated porous sandstone," Exploration Geophysics, vol. 35, pp. 25-32, 2004.

[15] Z. Xue and X. Lei, "Laboratory study of $\mathrm{CO}_{2}$ migration in water-saturated anisotropic sandstone, based on $\mathrm{P}$-wave velocity imaging," Exploration Geophysics, vol. 37, pp. 10-18, 2006.

[16] J. Q. Shi, Z. Xue, and S. Durucan, "Seismic monitoring and modelling of supercritical $\mathrm{CO}_{2}$ injection into a water-saturated sandstone: Interpretation of P-wave velocity data," International Journal of Greenhouse Gas Control, vol. 1, no. 4, pp. 473-480, 2007.

[17] X. Lei and Z. Xue, "Ultrasonic velocity and attenuation during $\mathrm{CO}_{2}$ injection into water-saturated porous sandstone: measurements using difference seismic tomography," Physics of the Earth and Planetary Interiors, vol. 176, no. 3-4, pp. 224234, 2009.

[18] J. Kim, Z. Xue, and T. Matsuoka, "Experimental study on $\mathrm{CO}_{2}$ monitoring and saturation with combined P-wave velocity and resistivity," in International Oil and Gas Conference and Exhibition (IOGCEC'10), pp. 312-319, June 2010.

[19] A. F. Siggins and D. N. Dewhurst, "Saturation, pore pressure and effective stress from sandstone acoustic properties," Geophysical Research Letters, vol. 30, no. 2, pp. 61-1-61-4, 2003. 
[20] A. F. Siggins, "Velocity-effective stress response of $\mathrm{CO}_{2}$-saturated sandstones," Exploration Geophysics, vol. 37, pp. 60-66, 2006.

[21] A. F. Siggins, M. Lwin, and P. Wisman, "Laboratory calibration of the seismo-acoustic response of $\mathrm{CO}_{2}$ saturated sandstones," International Journal of Greenhouse Gas Control, vol. 4, no. 6, pp. 920-927, 2010.

[22] N. I. Christensen and H. F. Wang, "The influence of pore pressure and confining pressure on dynamic elastic properties of Berea sandstone," Geophysics, vol. 50, no. 2, pp. 207-213, 1985.

[23] R. Hofmann, X. Xu, M. Batzle, M. Prasad, A. K. Furre, and A. Pillitteri, "Effective pressure or what is the effect of pressure?" Leading Edge, vol. 24, no. 12, pp. 1256-1260, 2005.

[24] X. Xu, R. Hofmann, M. Batzle, and T. Tshering, "Influence of pore pressure on velocity in low-porosity sandstone: implications for time-lapse feasibility and pore-pressure study," Geophysical Prospecting, vol. 54, no. 5, pp. 565-573, 2006.

[25] M. A. Capello, Geology and rock physics of the San Andres Formation in Vacuum Field, New Mexico, M.S. thesis, Colororado School of Mines, 1995.

[26] L. Duranti, Time-lapse multicomponent seismic analysis of reservoir dynamics, Ph.D. dissertation, Colorado School of Mines, 2001.

[27] L. T. Brown, Integration of rock physics and reservoir simulation for the interpretation of time-lapse seismic data at Weyburn Field, Saskatchewan, M.S. thesis, Colorado School of Mines, 2002.

[28] H. Yamamoto, Using time-lapse seismic measurments to improve ow modeling of $\mathrm{CO}_{2}$ injection in the Weyburn Field: a naturally fractured, layered reservoir, Ph.D. dissertation, Colorado School of Mines, 2004.

[29] E. Rojas, Elastic rock properties of tight gas sandtones for reservoir characterization at Rulison Field, Colorado, M.S. thesis, Colorado School of Mines, 2005.

[30] Z. Wang and A. M. Nur, "Effects of $\mathrm{CO}_{2}$ flooding on wave velocities in rocks with hydrocarbons," SPE Reservoir Engineering, vol. 4, no. 4, pp. 429-436, 1989.

[31] S. Sonnenberg, "Tectonic and sedimentation model for Morrow sandstone deposition, Sorrento Field, Denver Basin, Colorado," Mountain Geologist, vol. 22, pp. 180-191, 1985.

[32] J. Benton, "Subsurface stratigraphic analysis, Morrow (Pennsylvanian), North Central Texas County, Oklahoma," The Shale Shaker Digest VII, vol. 21-23, pp. 1-28, 1973.

[33] T. D. Jobe, Optimizing geo-cellular reservoir modeling in a braided river incised valley fill: Postle Field, Texas County, Oklahoma, M.S. thesis, Colorado School of Mines, 2010.

[34] A. E. Heris, Integrated ow simulation and time-lapse seismic reservoir characterization in an enhanced oil recovery project, Postle Field, Texas County, Oklahoma, Ph.D. dissertation, Colorado School of Mines, 2011.

[35] W. Wang, M. Batzle, and A. Wandler, "Effects of $\mathrm{CO}_{2}$ on brine, gas, and oil properties," in 2009 Annual Meeting of Fluid/DHI, Rock Physics Lab, University of Houston and Center for Rock Abuse, Colorado School of Mines, 2009.

[36] T. Mori and K. Tanaka, "Average stress in matrix and average elastic energy of materials with misfitting inclusions," Acta Metallurgica, vol. 21, no. 5, pp. 571-574, 1973.

[37] Y. Benveniste, "A new approach to the application of MoriTanaka's theory in composite materials," Mechanics of Materials, vol. 6, no. 2, pp. 147-157, 1987.

[38] G. Mavko, "Expert answers," CSEG Recorder, vol. 30, no. 5, pp. $8-12,2005$.
[39] P. Singh and T. Davis, "Advantages of shear wave seismic in Morrow sandstone detection," International Journal of Geophysics, vol. 2011, Article ID 958483, 16 pages, 2011. 

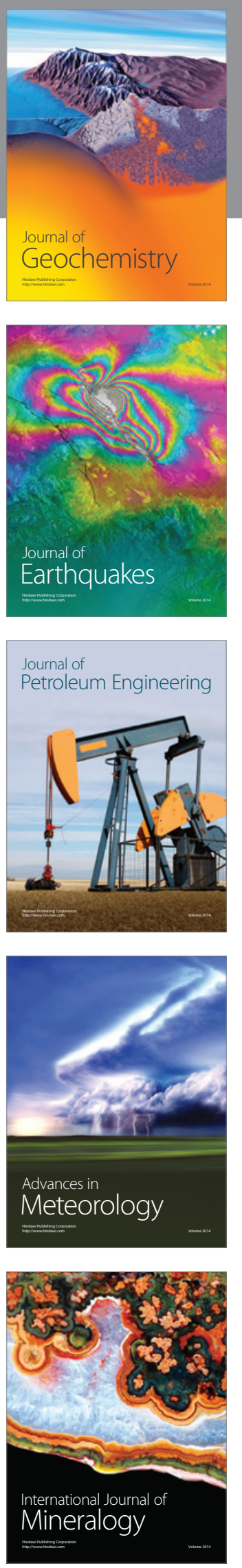
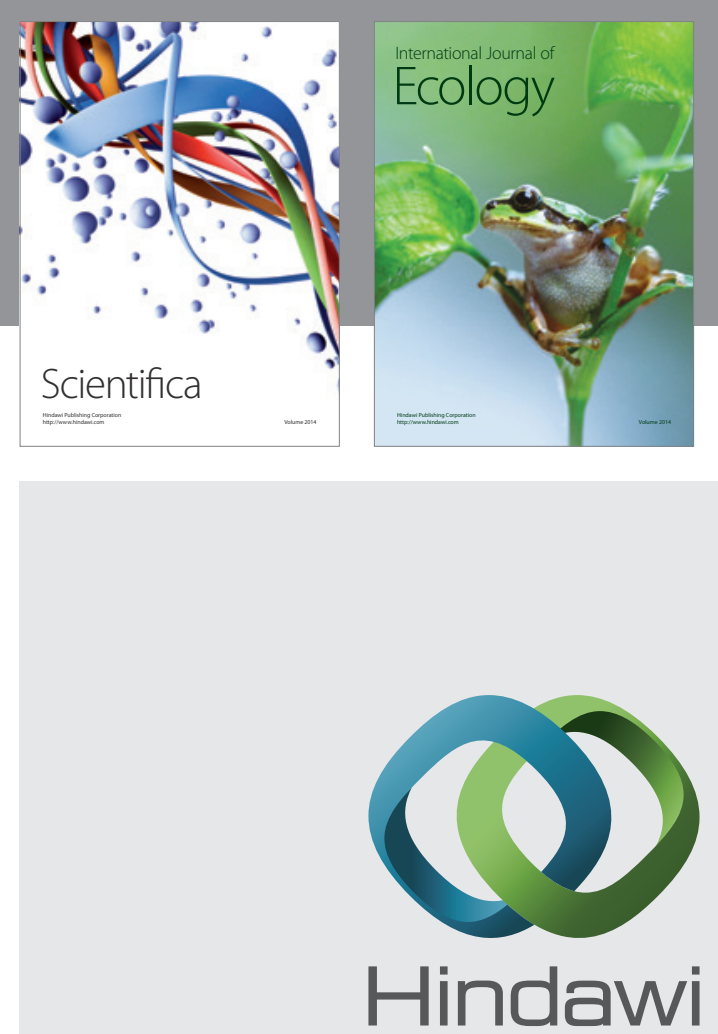

Submit your manuscripts at http://www.hindawi.com
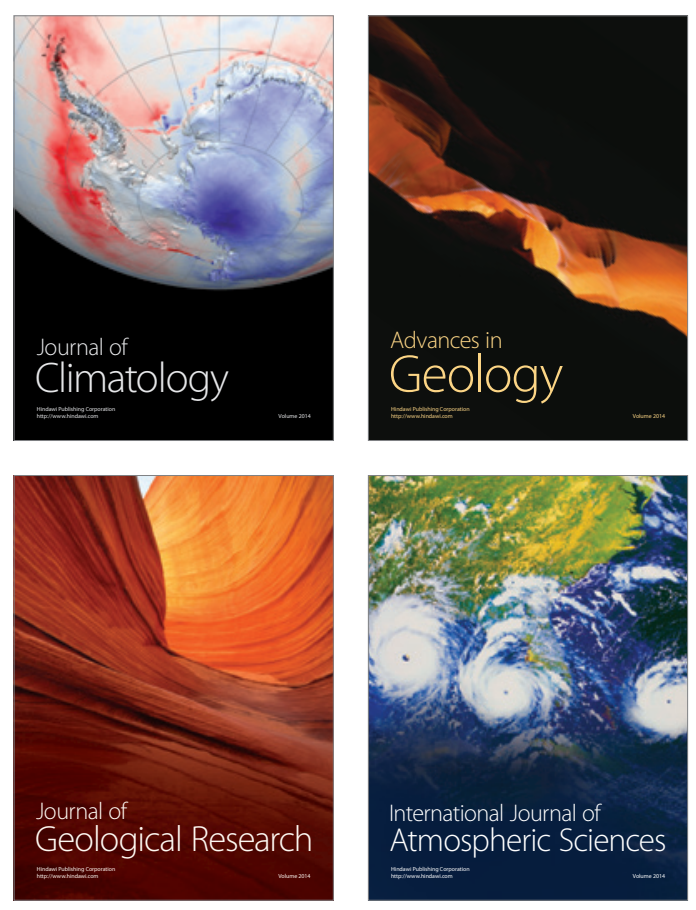
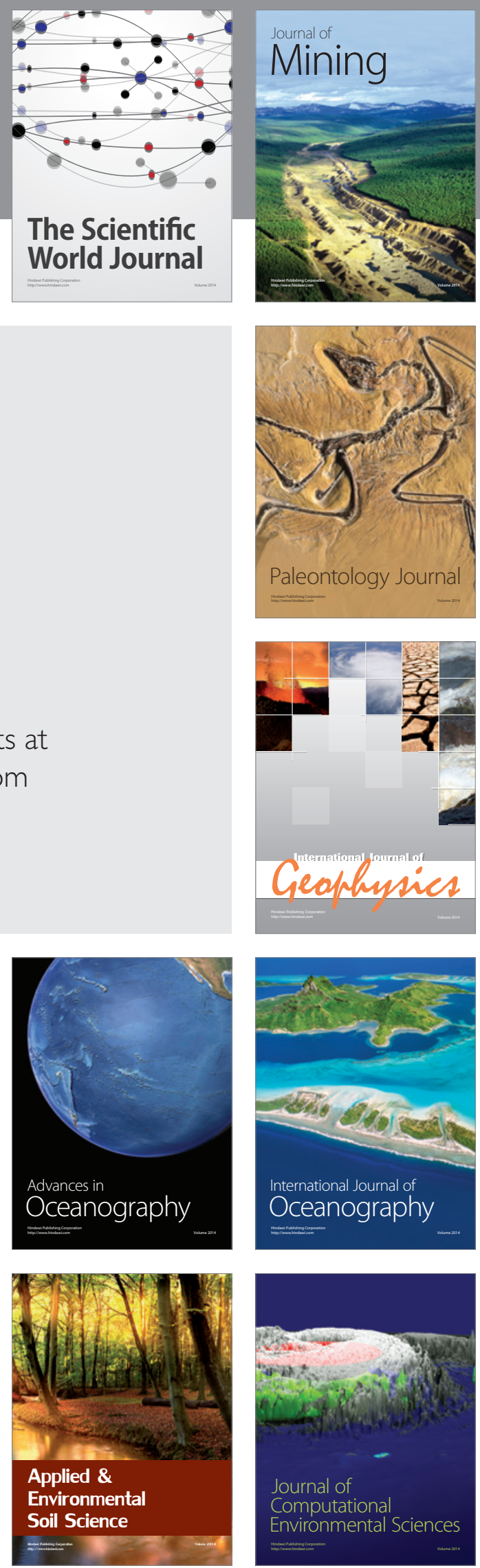